\title{
Visible light-photoreactive composite surfaces with thermoresponsive wetting and photocatalytic properties
}

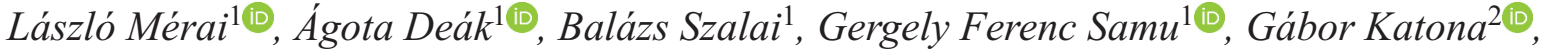

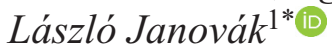 \\ ${ }^{1}$ University of Szeged, Department of Physical Chemistry and Materials Science, H-6720 Rerrich Béla tér 1, Szeged, \\ Hungary \\ ${ }^{2}$ University of Szeged, Faculty of Pharmacy, Institute of Pharmaceutical Technology and Regulatory Affairs, H-6720 \\ Eötvös u. 6, Szeged, Hungary
}

Received 15 June 2021; accepted in revised form 17 August 2021

\begin{abstract}
With the increasing demand for liquid manipulation and microfluidic techniques, surfaces with external stimuli induced real-time tunable wetting properties are getting into the focus of materials science research. In this study, we present poly(dimethylsiloxane) (PDMS) copolymer-based composite coatings with thermally adjustable wetting and visible-light photoreactivity. To give thermal responsivity to the spray-coated or doctor blade-casted PDMS surfaces, they were grafted with poly $(N$-isopropylacrylamide) (PNIPAAm), applying the Activators Regenerated by Electron Transfer - Atom Transfer Radical Polymerization (ARGET-ATRP) method. As the lower critical solution temperature (LCST) of the grafted PNIPAAm chains appeared to be $34^{\circ} \mathrm{C}$, the copolymer films showed thermoresponsive, and PNIPAAm surface concentration-dependent wetting characteristics. The addition of $15 \mathrm{wt} \%$ visible light-active plasmonic $\mathrm{Ag}-\mathrm{TiO}_{2}$ photocatalyst nanoparticles $\left(d_{\text {primary }}\right.$ $\sim 50 \mathrm{~nm}$ ) enriched the coatings with photocatalytic activity, which was also proven to be temperature-dependent during methylene-blue (MB; $c_{0}=6.25 \mathrm{mM}$ ) photodegradation tests (blue LED-light, $\lambda=405 \mathrm{~nm}$ ) at the S/L-interface. Thanks to the real-time tunable wetting and photocatalytic properties, the presented coatings may offer a novel route towards sophisticated liquid manipulation.
\end{abstract}

Keywords: polymer composites, stimulus-responsive, photodegradation, smart polymers, coatings

\section{Introduction}

Stimulus-responsive polymers and their composites are popular subjects of modern materials science $[1$, 2]. Among many, they are utilized as pH-responsive intelligent drug delivery and release systems [3], photo- or electroresponsive actuators [4,5], or even multistimulus-responsive biointerfaces [6]. The stimulus-responsivity of such composites can influence many properties, like shape, size [7], density, swelling degree, and the real-time regulation of surface wetting properties. Latter attracted specific attention in recent years due to the increasing popularity of microfluidic and liquid manipulation devices.
The wetting characteristics of a surface may be manipulated by altering surface charge excess, functionality, roughness, or topology [8,9]: all of these can be subjected to external stimuli, ranging, for example, from the applications of electrowetting [5], to roughness-changing magnetorheological elastomers [10] and liquid manipulator magnetic pillar systems [11, 12]. In a widely known approach, the wetting properties of a solid surface become tunable through its functionalization with poly ( $N$-isopropylacrylamide) (PNIPAAm). The PNIPAAm-water systems have lower critical solution temperature (LCST) at $\sim 32^{\circ} \mathrm{C}$, which means excellent dissolution and wetting 
below this temperature but precipitation and dewetting at temperatures exceeding this value [13]. The popularity of PNIPAAm originates from the facts that these polymer chains are easy-to-anchor to many organic and inorganic substrates [14-17], even to the surface of different micro- and nanoparticles [18] and the tunability of LCST through copolymerization with different monomers [19-21]. This versatility of PNIPAAm led to the development of intelligent drug delivery systems as the drug release can be regulated by the temperature of the target organs or the inflamed tissue in real-time [22], but PNIPAAm-hydrogel-based thermoresponsive actuators also exist [23]. To achieve as narrow transition temperature ranges as possible (to get a well-defined LCST value), the provision of monodispersity to the surface covering PNIPAAm chains is substantial [24]. Monodisperse PNIPAAm can form during living polymerization processes, such as atomic transfer radical polymerization (ATRP); however, the success of the original ATRP methods is hindered by many difficulties as the reaction mixtures should be purified and isolated before and during the synthesis. The advancements in the field of ATRP-techniques led to more easily implementable synthetic routes: for example, Shivapooja et al. [25] successfully utilized the ARGET-ATRP (Activators Regenerated by Electron Transfer) method to grow monodisperse PNIPAAm chains on silicon surfaces, which resulted in thermoresponsive wetting characteristics. An analogous method can be applied in the case of organic substrates such as poly(dimethylsiloxane) (PDMS), as well [26]. These approaches require halogen-terminated surface-bound ATRP-initiators. For example, in the case of PDMS can be connected to the PDMS network during curing due to their initially unsaturated nature (presence of double bonds) [24].

Although, the wetting transitions of different PNIPAAm-functionalized surfaces are widely studied and well documented [27-30], the literature still lacks in the descriptions of these systems in wettingrelated applications, such as heterogeneous photocatalysis, where both the wetting of a surface by the liquid medium and the adsorption affinity towards the reactant can be rate-determining. In the few existing approaches, inorganic semiconductor photocatalyst nanoparticles such as $\mathrm{Cu}_{2} \mathrm{O}$ [18] or $\mathrm{ZnO}$ [31] were functionalized with PNIPAAm, resulting in increased colloidal stability and temperature-dependent photodegradation efficiency against model organic pollutants. Despite these colloidal systems show tunable photocatalytic activity, there has been no example of tunable photocatalytic efficiency in the case of PNIPAAm-functionalized macroscopic surfaces with thermoresponsive wetting properties, so far. As it is relatively difficult to separate the dispersing medium and the disperse phase in practice, the application of macroscopic surfaces with real-time tunable photocatalytic performance would be more beneficial in terms of simplicity and reusability.

To fill the gap in the literature for surfaces with thermally-tunable wetting and visible light-active photocatalytic performance, we present easy-to-prepare PNIPAAm-grafted PDMS coatings, containing visible light-photoreactive plasmonic $\mathrm{Ag}-\mathrm{TiO}_{2}$ photocatalyst nanoparticles. The wetting properties of the composite surfaces can be adjusted by the temperature and by changing the monomer and/or the initiator loading during the ARGET-ATRP grafting of PDMS films with PNIPAAm. Moreover, the embedded photocatalyst content resulted temperature-dependent photodegradation-efficiency for the $\mathrm{Ag}-\mathrm{TiO}_{2}$ containing smart composite layer during methyleneblue degradation tests at the S/L-interface.

\section{Materials and methods \\ 2.1. Synthesis of the 10-undecenyl 2-bromoisobutyrate surface ATRP initiator (INI)}

The 10-undecenyl 2-bromoisobutyrate (initiator; INI) was synthesized according to a modified version of a previously published method [32]. A stir bar, $5.9 \mathrm{ml}$ (29.5 mmol) 10-undecen-1-ol (Aldrich; 98\%), $5.3 \mathrm{ml}$ (38 mmol) triethylamine (TEA) (Fluka; Buchs, Schwitzerland; a.r.), and $50 \mathrm{ml}$ dichloromethane (DCM) (Molar Chemicals; Halásztelek, Hungary; a.r., predried over anhydrous $\mathrm{Na}_{2} \mathrm{SO}_{4}$ (Reanal; Budapest, Hungary; puriss)) were added to a $100 \mathrm{ml}$ round bottom flask in an ice bath. $3.7 \mathrm{ml}(29.9 \mathrm{mmol}) 2$-bromoisobutyryl bromide (Sigma-Aldrich; Schnelldorf, Germany; 98\%) were added dropwise; then, the flask was removed from the ice bath and stirred at room temperature for $24 \mathrm{~h}$. The solution was washed with $65 \mathrm{ml}$ of $0.5 \mathrm{M} \mathrm{HCl}$ (Molar Chemicals; Halásztelek, Hungary; a.r.) and with $65 \mathrm{ml}$ deionized water 3 times; then, the organic solvent was removed by rotary evaporator. The solution was run through a column of $60 \mathrm{ml}$ silica gel (Kieselgel-G; Reanal, Budapest, Hungary) with $100 \mathrm{ml} \mathrm{n}$-hexane (Molar Chemicals; Halásztelek, Hungary; technical grade) eluent. 
At last, the eluent was removed with the help of a rotary evaporator to obtain the product in the form of $6.08 \mathrm{~g}$ ( $\sim 65 \%$ yield) yellowish clear liquid. The chemical structure and the purity of the product was evidenced by ${ }^{1} \mathrm{H}$ - and ${ }^{13} \mathrm{C}-\mathrm{NMR}$ spectroscopy [26] in benzene- $d_{6}$ (Sigma-Aldrich; Schnelldorf, Germany) solvent.

\section{NMR spectral data:}

${ }^{1} \mathrm{H}-\mathrm{NMR}\left(500 \mathrm{MHz}, \mathrm{C}_{6} \mathrm{D}_{6}\right), \delta[\mathrm{ppm}]: 5.77-5.83(\mathrm{~m}$, $1 \mathrm{H},=C H), 4.98-5.07\left(\mathrm{~d}, 2 \mathrm{H},=\mathrm{CH}_{2}\right), 3.97-4.00(\mathrm{t}$, $\left.2 \mathrm{H},-\mathrm{CH}_{2} \mathrm{O}\right), 1.97-2.01\left(\mathrm{~m}, 2 \mathrm{H},=\mathrm{CHCH}_{2}\right), 1.75(\mathrm{~s}$, $\left.6 \mathrm{H},-\mathrm{CH}_{3}\right), 1.37-1.46\left(\mathrm{~m}, 2 \mathrm{H},-\mathrm{CH}_{2} \mathrm{CH}_{2} \mathrm{O}\right), 1.29-$ $1.35\left(\mathrm{~m}, 2 \mathrm{H},-\mathrm{CH}_{2} \mathrm{CH}_{2} \mathrm{CH}_{2} \mathrm{O}\right), 1.14-1.23(\mathrm{~m}, 10 \mathrm{H}$, $\left.-\mathrm{CH}_{2} \mathrm{CH}_{2} \mathrm{CH}_{2} \mathrm{CH}_{2} \mathrm{CH}_{2}-\right)$

${ }^{13} \mathrm{C}-\mathrm{NMR}$ (125 MHz, $\left.\mathrm{C}_{6} \mathrm{D}_{6}\right), \delta[\mathrm{ppm}]: 171.04$ $(\mathrm{O}=\mathrm{C}-\mathrm{O}), 138.86\left(\mathrm{CH}=\mathrm{CH}_{2}\right), 127.74 \quad\left(\mathrm{C}_{6} \mathrm{D}_{6}\right)$, $114.23\left(=\mathrm{CH}_{2}\right), 65.65\left(-\mathrm{CH}_{2}-\mathrm{O}\right), 55.83(\mathrm{C}-\mathrm{Br})$, $33.86\left(\mathrm{CH}_{2}-\mathrm{CH}=\mathrm{CH}_{2}\right), 33.85 \quad\left(-\mathrm{CH}_{3}\right), 30.39$, $29.42, \quad 29.38, \quad 29.10, \quad 28.96, \quad 28.29, \quad 25.69$ $\left(-\mathrm{CH}_{2} \mathrm{CH}_{2} \mathrm{CH}_{2} \mathrm{CH}_{2} \mathrm{CH}_{2} \mathrm{CH}_{2} \mathrm{CH}_{2} \mathrm{CH}_{2}-\right)$

\subsection{Synthesis of PDMS-co-INI and \\ $\mathrm{Ag}^{-\mathrm{TiO}_{2}} / \mathrm{PDMS}-\mathrm{co}$-INI samples}

As an elastic and hydrophobic base polymer material, two-component Elastosil C1200 PDMS elastomer (Wacker; Burghausen, Germany) was used: component A contains the silicone-hydride prepolymer and the vinyl-terminated crosslinker, while component B contains the prepolymer alongside the Pt-complex catalyst for the curing reaction [11]. In each of our formulations, we kept the recommended 1:1 massto-mass ratio of A and $\mathrm{B}$.

To study the elastic properties of PDMS-co-INI polymers, cylindrical bulk samples $(h=0.5 \mathrm{~cm}, d=$ $2.5 \mathrm{~cm}$ ) were prepared with 11:0, 11:0.13, 11:0.25 or 11:0.5 PDMS-to-initiator mass-to-mass ratios $(0$, $1.2,2.2$ and $4.35 \mathrm{wt} \%$ INI, respectively). The mixtures were cured at $70^{\circ} \mathrm{C}$ for $2 \mathrm{~h}$ in an oven, and then the samples were left at rt. for $24 \mathrm{~h}$. To remove initiator residues, each cross-linked sample was immersed in $40 \mathrm{ml}$ of cyclohexane (Carlo Erba, Sabadell, Spain; $99.8 \%$ ) for another $24 \mathrm{~h}$, then was washed with $2 \times 20 \mathrm{ml}$ cyclohexane and dried at $\mathrm{rt}$.

For grafting polymerization studies, the doctor blade method was utilized: $2.5 \times 2.5 \mathrm{~cm}^{2}$ and $200 \mu \mathrm{m}$ thick

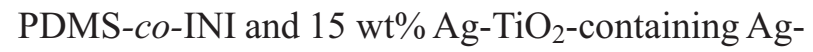
$\mathrm{TiO}_{2} / \mathrm{PDMS}$-co-INI layers $(0,1.2$, or $4.35 \mathrm{wt} \% \mathrm{INI})$ were prepared on clean glass substrates, applying a stainless steel Zehntner ZAF 2010.8050 (Zehntner;
Schissach, Switzerland) applicator frame. The polymer films were cured at $70^{\circ} \mathrm{C}$ for $2 \mathrm{~h}$ in an oven, then were left for $24 \mathrm{~h}$ at room temperature, and then were rinsed with $2 \times 10 \mathrm{ml}$ cyclohexane and dried at room temperature. The synthesis of $\mathrm{Ag}-\mathrm{TiO}_{2}$ plasmonic photocatalyst particles is detailed in our previous publications [33-35].

\subsection{ARGET-ATRP synthesis of PDMS-gr-PNIPAAm and Ag-TiO ${ }_{2} /$ PDMS-gr-PNIPAAm samples}

To functionalize the PDMS-co-INI layers with PNIPAAm, a previously published method was applied with minor modifications [25]. Glass beakers containing the PDMS-co-INIC or Ag-TiO $2 / \mathrm{PDMS}-$ co-INIC layers on glass substrates were charged with $0.30,0.60,1.25,2.50,5.00,6.25,7.50$ or $10.0 \mathrm{M}$ NIPAAm monomer (Sigma-Aldrich; Schnelldorf, Germany; 97\%), 18 mg CuBr 2 (Sigma-Aldrich; 99\%) and $20 \mu 1 N, N, N^{\prime}, N^{\prime \prime}, N^{\prime}$-Pentamethyldiethylenetriamine (PMDETA) (Sigma-Aldrich; 99\%) dissolved in $6 \mathrm{ml} \mathrm{1:1} \mathrm{(volume-to-volume} \mathrm{ratio)} \mathrm{water/MeOH}$ (Molar Chemicals; Halásztelek, Hungary; a.r.) mixture. As a reducing agent, $28 \mathrm{mg} \mathrm{L}$-ascorbic acid (Molar Chemicals; a.r.) was used in each case. The polymerization was initiated by the addition of the reducing agent to the reaction mixture. After allowing the reaction to propagate at $\mathrm{rt}$. for $24 \mathrm{~h}$, the samples were rinsed with $6 \times 50 \mathrm{ml}$ deionized water and dried at rt.

For the purpose of photocatalytic tests, $2.5 \times 2.5 \mathrm{~cm}^{2}$, $d=19 \mathrm{mg} / \mathrm{cm}^{2}$ spray-coated layers of $\mathrm{Ag}-\mathrm{TiO}_{2} /$ PDMS- $g r$-PNIPAAm (1.2 wt\% INI, 5 M NIPAAm, $15 \mathrm{wt} \% \mathrm{Ag}-\mathrm{TiO}_{2}$ ) were prepared. During the preparation process, suspensions were prepared with a total of $1.5 \mathrm{~g}$ of the raw materials (PDMS, INI, Ag$\mathrm{TiO}_{2}$ ) in $10 \mathrm{ml}$ toluene. The mixtures were evenly sprayed on glass substrates from a $15 \mathrm{~cm}$ distance using a type R180 Airbrush spray gun at an operating nitrogen gas pressure of 3 bar.

\subsection{Characterization methods}

Oscillatory rheology

The elastic properties of PDMS-co-INI bulk samples were studied during oscillatory rheology measurements (Anton Paar Physica MCR 301; Anton Paar; Graz, Austria) at $25 \pm 0.1^{\circ} \mathrm{C}$, applying the $\mathrm{PP} 20$ probe with $1-1.2 \mathrm{~mm}$ gap width. The storage $\left(G^{\prime}\right)$ and loss $\left(G^{\prime \prime}\right)$ moduli were measured while constantly increasing the load on the samples (in the $0.01-1000 \%$ 
deformation range), with the applied angular frequency of $10 \mathrm{~s}^{-1}$.

\section{Contact angle measurement and surface free energy determination}

To measure the temperature-dependency of the apparent static contact angles (c.a. or $\Theta$ ) of the layers, a drop shape analysis system was applied (EasyDrop;

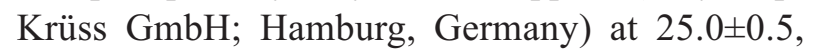
$40.0 \pm 0.5,50.0 \pm 0.5$, and $60.0 \pm 0.5^{\circ} \mathrm{C}$, equipped with a TC40-MK2 Peltier Temperature Assembly (Krüss) and a TC3013 Digital Thermometer (Krüss). The $4 \pm 1 \mu 1$ drop of deionized water was made on the sample with the use of a syringe equipped with a stainless-steel needle. Using the CCD camera of the goniometer, the drop contour in the taken photographs was mathematically described by the Young-Laplace equation using DSA100 software, and the $\Theta$ was determined as the slope of the contour line at the threephase contact point. The c.a. values were measured right after the drop placement (initial contact angle) and after 1 min with 8 parallel measurements in each case.

The advancing $\left(\Theta_{\text {adv }}\right)$ and receding $\left(\Theta_{\text {rec }}\right)$ contact angles were also measured, applying the protocol of Drelich [36]. According to the theory of Chibowski [37], the surface free energy $\left(\gamma_{\mathrm{s}}^{\mathrm{tot}}\right)$ can be determined by exploiting the phenomenon of contact angle hysteresis on the basis of $\Theta_{\text {adv }}$ and $\Theta_{\text {rec }}$ data, knowing the surface tension of the probe liquid $\left(\gamma_{1}\right.$, in case of deionized water it was $72.00 \mathrm{mN} / \mathrm{m}$ at $25^{\circ} \mathrm{C}$ and $60.76 \mathrm{mN} / \mathrm{m}$ at $50^{\circ} \mathrm{C}$ ). The $\gamma_{\mathrm{s}}^{\text {tot }}$ values were obtained by the help of the Equation (1):

$\gamma_{\mathrm{s}}^{\text {tot }}=\gamma_{1} \cdot \frac{\left(1+\cos \Theta_{\mathrm{adv}}\right)^{2}}{\left(2+\cos \Theta_{\mathrm{rec}}+\cos \Theta_{\mathrm{adv}}\right)}$

\section{Thermoanalytical measurements}

The lower critical solution temperature (LCST) of grafted PNIPAAm chains on PDMS-co-INI layers was investigated via differential scanning calorimetry (DSC) analysis. The samples were heated from 25 to $50^{\circ} \mathrm{C}$ and then cooled back to $25^{\circ} \mathrm{C}$ at a heating/ cooling rate of $2{ }^{\circ} \mathrm{C} / \mathrm{min}$ (Mettler-Toledo DSC 822e Instrument; Mettler-Toledo; Colombus, OH, USA) in sealed aluminum sample holders. In the case of each sample, the sample holder contained $2.0 \pm 0.1 \mathrm{mg}$ of the corresponding layer, wetted by $20 \mu 1$ deionized water. The carrier gas was dry nitrogen at a flow rate of $50 \mathrm{ml} / \mathrm{min}$.
The thermogravimetry measurements were performed via Mettler-Toledo TGA/SDTA 851e instrument (Mettler-Toledo). During the measurements, the samples with $\sim 10 \mathrm{mg}$ initial weight were heated from 25 to $500^{\circ} \mathrm{C}$ at a heating rate of $5^{\circ} \mathrm{C} / \mathrm{min}$. The carrier gas was dry synthetic air at a flow rate of $50 \mathrm{ml} / \mathrm{min}$. The obtained thermoanalytical data was processed using STARe software in both cases.

\section{Electron microscopy}

The morphology and the elemental composition of the copolymer layers were examined by field emission scanning electron microscopy (SEM-Hitachi S-4700 microscope; Hitachi; Chiyoda City, Tokio, Japan), applying a secondary electron detector and 5,10 or $20 \mathrm{kV}$ acceleration voltage. The elemental analysis was performed based on energy-dispersive X-ray (EDX) spectra, recorded applying a RöntecEDS detector (Bruker; Berlin, Germany).

\section{X-ray photoelectron spectroscopy (XPS)}

The XPS-spectra were recorded applying a SPECS instrument (SPECS, Berlin, Germany), equipped with a PHOIBOS 150 MCD 9 hemispherical analyzer (SPECS; FAT-mode, $40 \mathrm{eV}$ pass energy for the survey and $20 \mathrm{eV}$ pass energy for the high-resolution spectra). The excitation of the samples was performed using the $\mathrm{Al} \mathrm{K} \mathrm{K}_{\alpha}(h v=1486.6 \mathrm{eV})$ emission of the double anode at $150 \mathrm{~W}$. During the spectra recordings, charge compensation $(0.5 \mathrm{eV} ; 0.3 \mathrm{~mA})$ was applied to set the position of the $\mathrm{O} 1 \mathrm{~s}$ reference line to $532.00 \mathrm{eV}$ binding energy value, which is characteristic to the Si-O-Si environment [38]. The spectral data were processed by the help of CasaXPS and Origin softwares.

\section{NMR-spectroscopy}

The NMR-spectra of the INI were recorded via a Bruker DRX 500 device (Bruker; Berlin, Germany), using $\mathrm{C}_{6} \mathrm{D}_{6}$ solvent and the characteristic $\mathrm{C}_{6} \mathrm{D}_{6}$ signal as an internal standard. The ${ }^{1} \mathrm{H}$-decoupled ${ }^{13} \mathrm{C}$-NMR spectra were recorded at $125 \mathrm{MHz}$ applying J-MOD pulse-sequence. The data was processed using MestReC software.

\section{Raman-microscopy}

Raman microscopy measurements were performed with a Thermo Scientific DXR Raman microscope (Thermo Fisher Scientific; Waltham, MA, USA). A laser-light of $780 \mathrm{~nm}$ wavelength was used, and its 
maximum power was $24 \mathrm{~mW}$. The microscopic lenses used for measurements were magnified $50 \times$, and the aperture was $25 \mu \mathrm{m}$. The examined chemical mapping area in the $200-3300 \mathrm{~cm}^{-1}$ Raman-shift range was $30 \times 30 \mu \mathrm{m}$; the vertical and horizontal step size was $1 \mu \mathrm{m}$. The instrument operation and the evaluation of the measurements were carried out with the help of the OMNIC for Dispersive Raman 8.2 software package (Thermo Fisher Scientific).

\section{Methylene-blue photodegradation tests}

Methylene-blue (MB; $c_{0}=2 \mathrm{mg} / \mathrm{dm}^{3}$ or $6.25 \mu \mathrm{M}$ ) photodegradation test were run at the $\mathrm{S} / \mathrm{L}$-interface. $2.5 \times 2.5 \mathrm{~cm}^{2}, 19 \mathrm{mg} / \mathrm{cm}^{2}$ specific mass spray-coated layers of $\mathrm{Ag}-\mathrm{TiO}_{2} / \mathrm{PDMS}-g r$-PNIPAAm $(1.2 \mathrm{wt} \%$ INI; 5 M NIPAAm) were placed in a $V=85 \mathrm{ml}$ custom-made stainless steel reactor, equipped with a heating mantle and a quartz window at the top. The MB solution in the reactor was kept in constant flow with the help of a peristaltic pump, with tubing of overall $15 \mathrm{ml}$ volume; therefore $100 \mathrm{ml} \mathrm{MB}$ solution was used in each experiment. Prior to the photocatalytic tests, the thermostated reactor $\left(25\right.$, or $\left.50^{\circ} \mathrm{C}\right)$, containing the composite layer (fixed on a clean microscope slide by $1 \times 1 \mathrm{~cm}^{2}$ double-sided adhesive tape) and the $100 \mathrm{ml} \mathrm{MB}$ solution was kept in the dark for $40 \mathrm{~min}$ to ensure the adsorption equilibrium of the test molecule. The $\mathrm{Ag}-\mathrm{TiO}_{2} / \mathrm{PDMS}-\mathrm{gr}$ PNIPAAm samples were illuminated by a blue-light LED lamp $\left(\lambda_{\max }=405 \mathrm{~nm}\right.$, General Electrics, Hungary) for $300 \mathrm{~min}$, placed at a distance of $5 \mathrm{~cm}$ from the layers. $3 \mathrm{ml}$ portions of MB solution were regularly sampled from the reactor by the help of a syringe, and the concentration decrease was monitored through spectrophotometry measurements (Red Tide SHIMADZU UV-1800 spectrophotometer; SHIMADZU, Kioto, Kioto Prefecture, Japan), applying a previously recorded calibration curve for absorbance values at $\lambda=660 \mathrm{~nm}$. The sampled portions of the MB solution were injected back into the reactor after the $\sim 2$ minutes-long spectra recordings. This sampling process resulted in less than $1 \%$ overall liquid volume decrease in the reactor after 5 hours of irradiation time throughout all measurements. Each photocatalytic experiment was conducted 3 times.

\section{Results and discussion}

\subsection{General sample characterization}

PDMS is an ideal candidate as a base material to form thermoresponsive surfaces as it is easy-to-process, has beneficial easy-to-tune elasticity, high chemical and mechanical resistance, and its cross-linked networks can easily be enhanced by covalently bound ATRP-initiators to promote surface PNIPAAmgrowth, which leads to the desired thermoresponsive wetting characteristics.

In our work, we chose 10-undecenyl 2-bromoisobutyrate (initiator; INI) as a PDMS-compatible ATRPinitiator, that has well-described synthetic methods and characteristics in the literature [32,39].

As Figure 1a shows, the INI is covalently bound to the PDMS-network by the Pt-complex catalyst content of the applied two-component Elastosil C1200 PDMS: besides keeping the optimal $(1: 1=\mathrm{m}: \mathrm{m})$ ratio between the two PDMS-component [11], the increasing amount of added INI can result in a drastic decline of cross-linking density and therefore, elasticity. According to a previous study, the optimal $\mathrm{m}: \mathrm{m}$ ratio between the PDMS and the INI is 11:0.13 $(1.2 \mathrm{wt} \% \mathrm{INI})$, and the recommended upper limit is 11:0.5 (4.3 wt\% INI) when Sylgard 184 PDMS is applied: if the INI-content is increased above this level, the resulting copolymer might have viscous characteristics [26]. The results of our oscillatory rheology measurements (sample modulus vs. deformation curves in Figure 1b) on bulk PDMS-co-INI samples support these statements: it can be seen on Figure 1c, that the storage $\left(G^{\prime}\right)$ and loss moduli $\left(G^{\prime \prime}\right)$ of the copolymers at $1 \%$ deformation show decreasing tendency with increasing INI-content, indicating a more viscous character as the cross-linking density decreases. The $G^{\prime}$ values range from 141000 to $5660 \mathrm{~Pa}$, and the $G^{\prime \prime}$ values range from 18000 to $2640 \mathrm{~Pa}$ with increasing INI content in the examined composition range (0-4.3 wt \% INI).

(4.3 wt \% INI) bulk samples and thin films were still acceptable to conduct contact angle (c.a.) measurements, and therefore this composition was also used in the following wetting studies to produce higher surface PNIPAAm-densities.

XPS measurements were performed to characterize the surface of the prepared samples (Figure 2). The survey scans (Figure 2a) reveal similar chemical composition for the PDMS-co-INI, PDMS- $g r$-PNIPAAm, and $\mathrm{Ag}-\mathrm{TiO}_{2} / \mathrm{PDMS}-\mathrm{g} r$-PNIPAAm films. The main chemical species present can be attributed to the PDMS matrix (C: 49.4 at $\%$; O: 24.2 at $\%$; Si: 26.3 at $\%$; Br: 0.1 at \%), with binding energies in good accordance with previously published results (Table 1 and 2) $[26,40]$. The high resolution scans reveal faint 


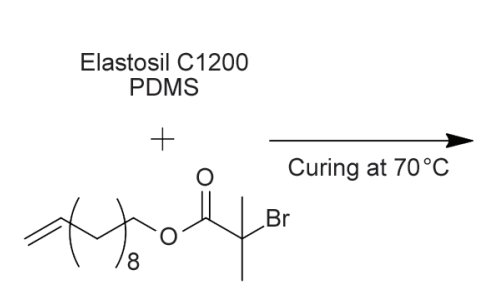

a)

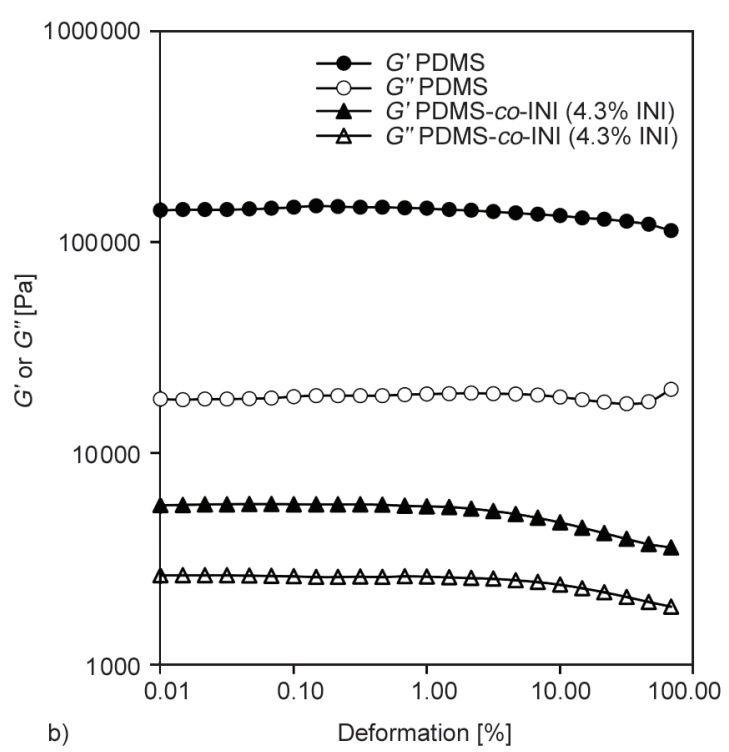

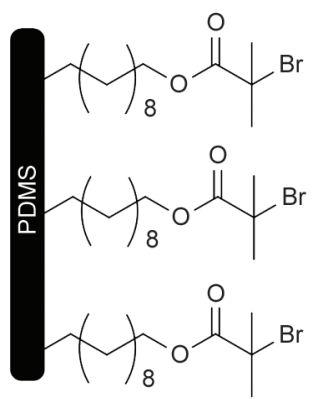
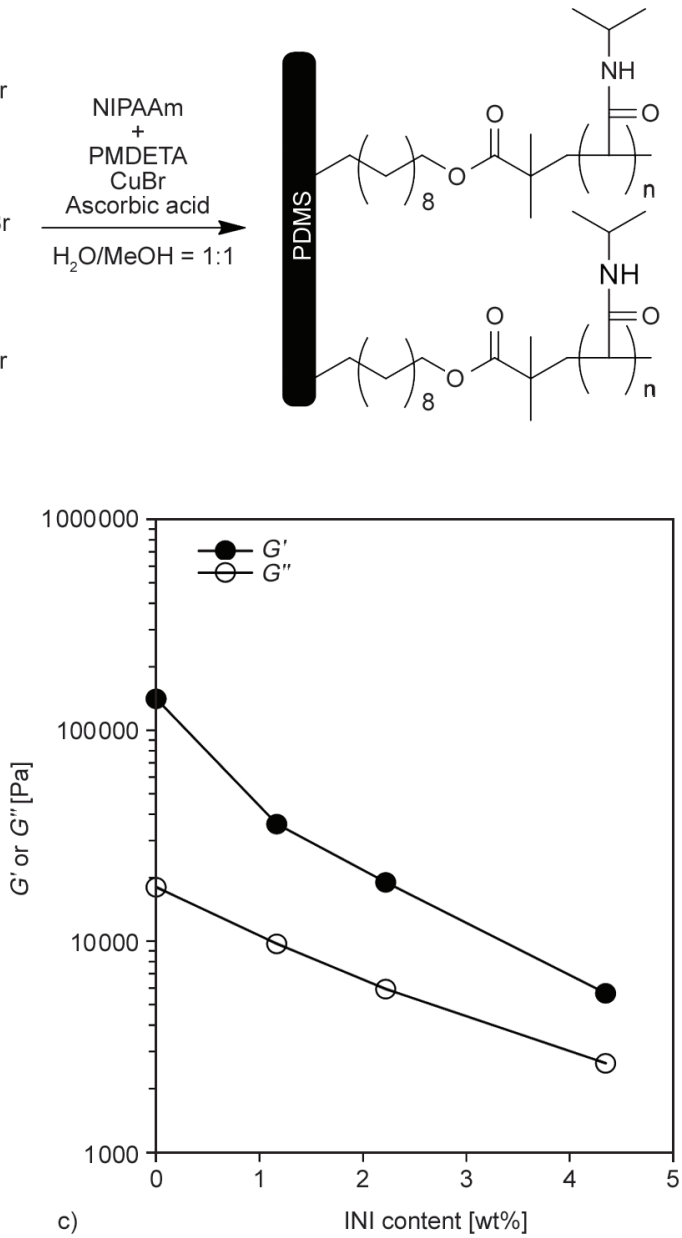

Figure 1. Schematic representation of the synthesis of PDMS-gr-PNIPAAm polymers (a), characteristic storage $\left(G^{\prime}\right)$ and loss $\left(G^{\prime \prime}\right)$ moduli of bulk pure PDMS and PDMS-co-INI (4.3 wt\% INI) samples $v s$. applied deformation (b), as well as the evolution of $G^{\prime}$ and $G^{\prime \prime}$ values of PDMS-INI copolymers as a function of INI-content at $1 \%$ deformation (c). However, in our case, the apparent elasticity and mechanical stability of PDMS-co-INI.

Table 1. Characteristic XPS peaks of PDMS-based doctor blade-casted layers (1.2 wt $\%$ INI; 5 M NIPAAm).

\begin{tabular}{|c|c|c|c|c|c|}
\hline Sample & $\begin{array}{l}\mathrm{C} 1 \mathrm{~s} \\
{[\mathrm{eV}]}\end{array}$ & $\begin{array}{l}\text { O 1s } \\
{[\mathrm{eV}]}\end{array}$ & $\begin{array}{c}\text { Si 2p } \mathbf{p}_{3 / 2} \\
{[\mathrm{eV}]}\end{array}$ & $\begin{array}{c}\mathrm{Br}_{3} \mathbf{3 d _ { 5 / 2 }} \\
{[\mathrm{eV}]}\end{array}$ & $\begin{array}{c}\text { Ti } 2 p_{3 / 2} \\
{[e V]}\end{array}$ \\
\hline PDMS-co-INI & 284.56 & 532.00 & 101.80 & 70.22 & - \\
\hline PDMS- $g r$-PNIPAAm & 284.45 & 532.00 & 101.75 & - & - \\
\hline Ag- $\mathrm{TiO}_{2} /$ PDMS- $g r$-PNIPAAm & 284.35 & 532.00 & 101.76 & - & 461.76 \\
\hline Literature value & 284.38 & 532.00 (BE ref) & 101.79 & 70.50 & 458.50 \\
\hline
\end{tabular}

Table 2. Elemental composition of different PDMS-based doctor blade-casted layers (1.2 wt $\%$ INI; 5 M NIPAAm) based on XPS spectral data.

\begin{tabular}{|l|c|c|c|}
\hline \multirow{3}{*}{ Element } & \multicolumn{3}{|c|}{$\begin{array}{c}\text { Elemental composition } \\
\text { [at\%] }\end{array}$} \\
\cline { 2 - 4 } & PDMS-co-INI & PDMS-gr-PNIPAAm & Ag-TiO $_{2}$ /PDMS-gr-PNIPAAm \\
\hline Silicon & 26.3 & 26.7 & 26.0 \\
\hline Oxygen & 24.2 & 24.0 & 23.6 \\
\hline Carbon & 49.4 & 49.3 & 50.2 \\
\hline Bromine & 0.1 & - & - \\
\hline Titanium & - & - & 0.2 \\
\hline
\end{tabular}



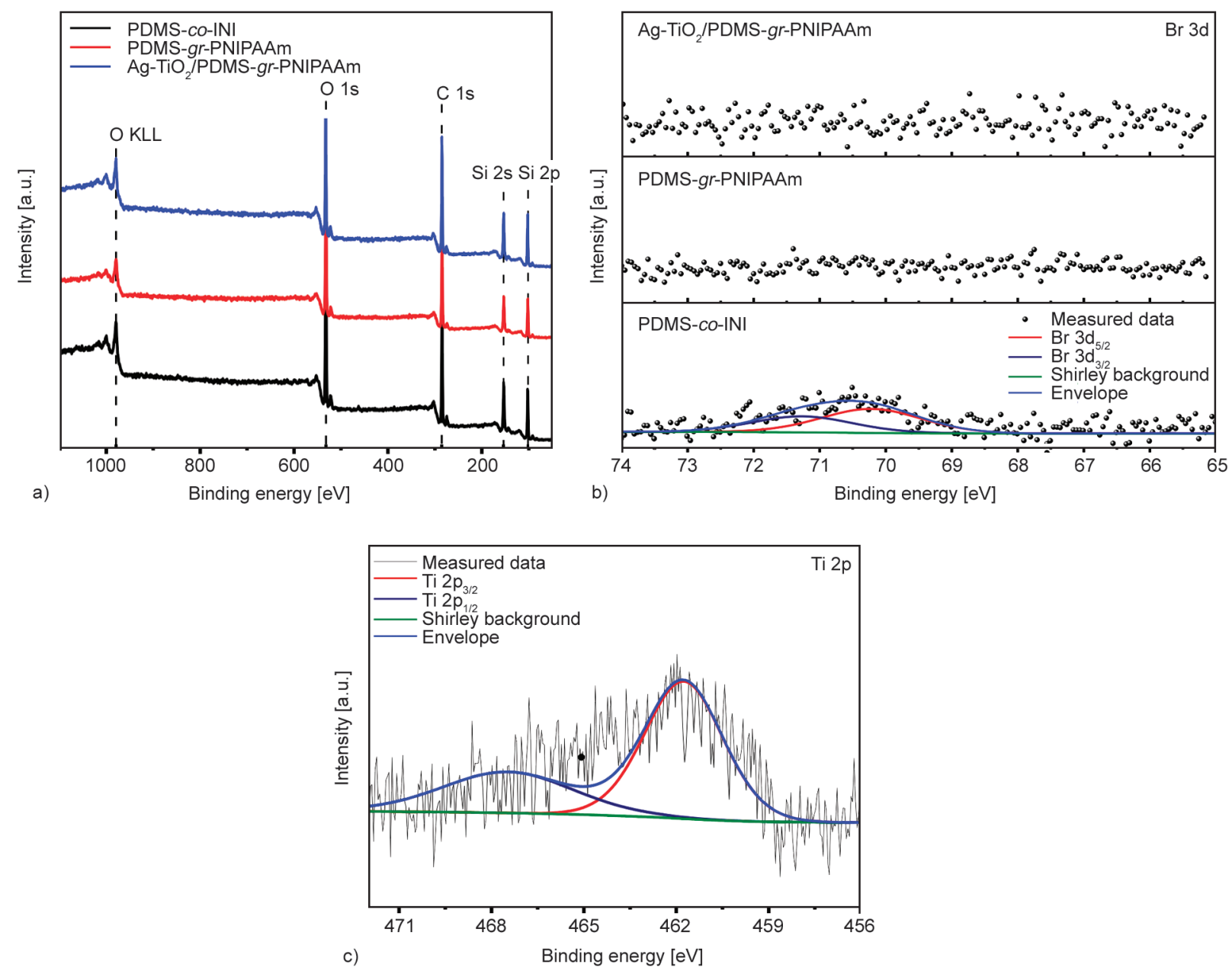

Figure 2. XPS-spectra of doctor blade-casted PDMS-co-INI, PDMS- $g r$-PNIPAAm and Ag- $\mathrm{TiO}_{2} / \mathrm{PDMS}$ - $r$-PNIPAAm films (4.3 wt\% INI; 5 M PNIPAAm) (a), indication of the Br 3d peak in all three samples (b), Ti 2p peak from the XPSspectrum of the $\mathrm{Ag}-\mathrm{TiO}_{2} / \mathrm{PDMS}-\mathrm{g} r$-PNIPAAm film (c).

$\mathrm{Br} 3 \mathrm{~d}$ core lines $(\sim 70.22 \mathrm{eV})$ which indicate the presence of covalently bound INI in the copolymer surfaces (Figure 2b).

The $200 \mu \mathrm{m}$ thin, doctor blade-casted PDMS-co-INI layers $(1.2$ or $4.3 \mathrm{wt} \%$ INI) were charged with different concentrations $(0.30,0.60,1.25,2.50,5.00$, $6.25,7.50$ or $10.00 \mathrm{M}$ ) of NIPAAm monomer solution during ARGET-ATRP grafting to achieve the desired thermoresponsive characteristics of the resulting PDMS- $g r$-PNIPAAm layers (Figure 1a). The successfulness of the grafting process is evidenced during the application of various spectroscopy methods on PDMS- $g r$-PNIPAAm (4.3 wt\% INI; $5 \mathrm{M}$ NIPAAm) films. As the Raman-spectra of Figure 3 show, the peak - characteristic to the double bond of NIPAAm - at $1622 \mathrm{~cm}^{-1}$ Raman-shift [41] diminishes during the grafting process; however, the $2958 \mathrm{~cm}^{-1}$ peak of the isopropyl group $(\mathrm{C}-\mathrm{H}$ symmetric stretching vibration) remains in the spectrum of the final product with high relative intensity, indicating the formation of the grafted polymer chains with relatively homogenous distribution (at $1 \mu \mathrm{m}$ lateral resolution) along the surface. This was evidenced via the relative intensity-mapping of the $2958 \mathrm{~cm}^{-1}$ peak (Figure 3). On the contrary, the XPS-spectra of the PDMS- $g r$-PNIPAAm layer does not indicate the presence of nitrogen atoms (Figure 2a) (possibly due to the low sensitivity of the technique towards nitrogen [42]) in the sample, and the elemental composition appeared to be very similar to the PDMS-co-INI films', however, the $\mathrm{Br} 3 \mathrm{~d}$ peak at $\sim 70.22 \mathrm{eV}$ binding energy diminishes after the grafting step, which can be attributed to the consumption of the surface initiator (Figure 2b).

The presence of PNIPAAm-associated surface nitrogen-content was evidenced by EDX-spectroscopy (Figure 4): as a result of monitoring the nitrogen $\mathrm{K}_{\alpha}(0,396 \mathrm{eV})$ line, the nitrogen-content of the surfacial layer was given to be $17.5 \pm 6.3 \%$ and homogenously distributed along the surface in the 


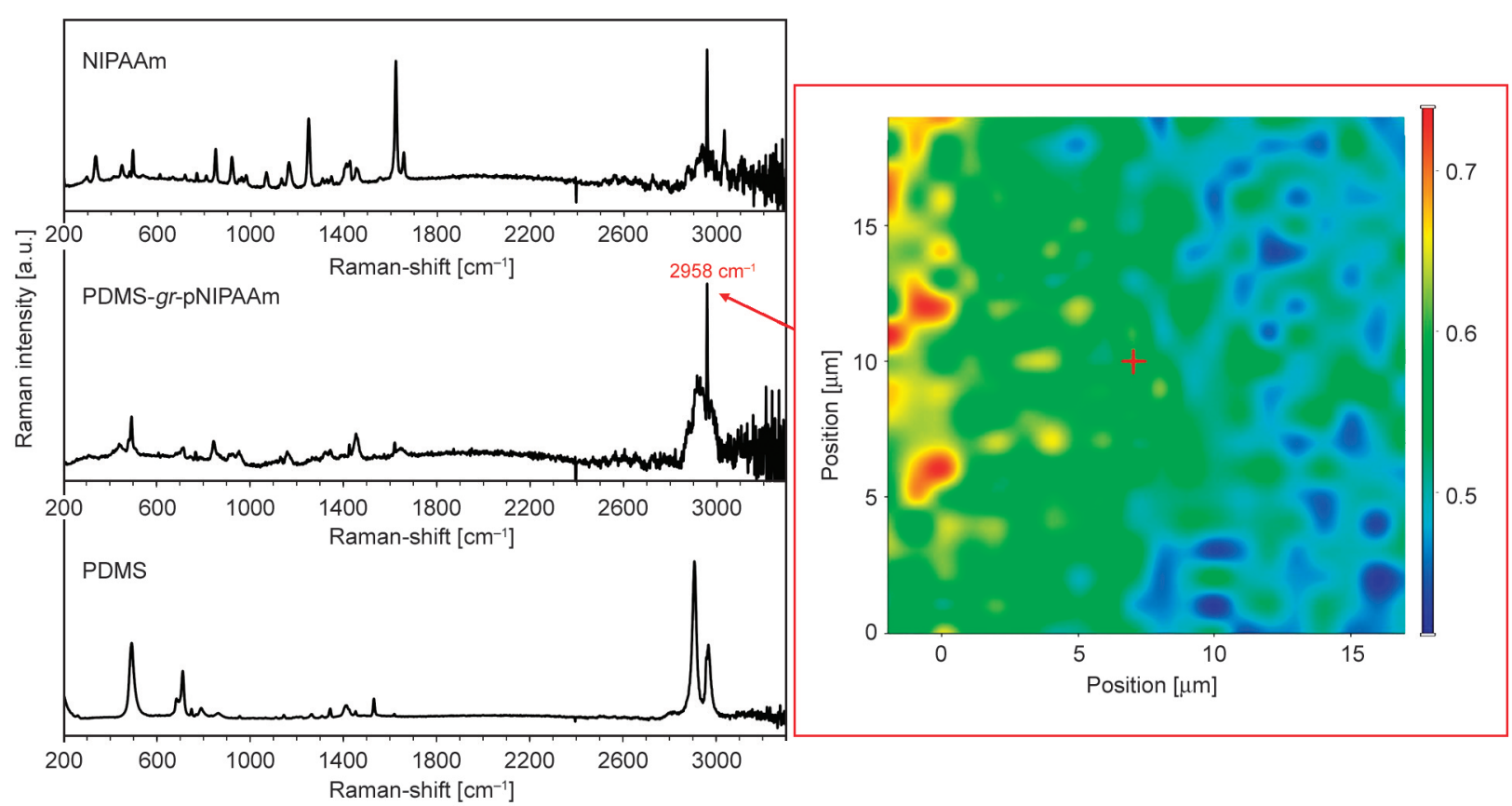

Figure 3. Raman-spectra of the NIPAAm, the initial PDMS and the PDMS- $g r$-PNIPAAm copolymer and the Raman-intensity heatmap of the peak with $2958 \mathrm{~cm}^{-1}$ Raman-shift along the surface of a PDMS- $g r$-PNIPAAm film $(4.3 \mathrm{wt} \% \mathrm{INI}$; 5 M NIPAAm).

case of PDMS-gr-PNIPAAm films, which is in good accordance with the results of Raman-mapping (Figure 3) The differences between the XPS and EDX elemental analysis results can be explained by the low sensitivity of XPS towards nitrogen [40] and the different depth-profile capabilities of the two techniques: as the photoelectrons (XPS) are originated from the upper $\sim 10 \mathrm{~nm}$ layer of the surface, the X-ray photons (EDX) can provide information on the composition of the upper 1-2 $\mu \mathrm{m}$ [43].

To enhance the thermoresponsive layers with visible light photocatalytic activity, plasmonic $\mathrm{Ag}-\mathrm{TiO}_{2}$ photocatalyst nanoparticles were incorporated into the PDSM/PNIPAAm copolymer matrices. As it is detailed in our previous publications, the catalyst and its composites exhibit visible light photoactivity $\left(\lambda_{\text {abs,max }} \sim 450 \mathrm{~nm} ; E_{\mathrm{g}}=3.08 \mathrm{eV}\right.$ band gap energy) with excellent photodegradation-efficiency against organic pollutants, and antimicrobial activity in many scenarios [33, 34, 44-46].

By dispersing $15 \mathrm{wt} \% \mathrm{Ag}-\mathrm{TiO}_{2}$ photocatalyst nanoparticles in the doctor blade-casted and spray-coated layers of PDMS-co-INI matrix, $\mathrm{Ag}-\mathrm{TiO}_{2} / \mathrm{PDMS}-\mathrm{co}$ INI composite layers were formed. Grafting these layers with PNIPAAm results in the formation of the so-called $\mathrm{Ag}-\mathrm{TiO}_{2} / \mathrm{PDMS}-g r$-PNIPAAm surfaces. As Figure 4 shows, the EDX-spectrum of $\mathrm{Ag}^{-\mathrm{TiO}_{2} /}$ PDMS- $g r$-PNIPAAm (1.2 wt $\%$ INI; 5 M NIPAAm) indicates the presence of titanium on the surface in a moderate amount $(\sim 1$ at $\%)$. This is in good accordance with the recorded XPS-spectra and elemental analysis (Figure $2 \mathrm{c}$ ), as the Ti $2 \mathrm{p}_{3 / 2}$ peak is visible at $461.76 \mathrm{eV}$ binding energy value greatly shifted to more positive values from the literature value of $\mathrm{Ti}(\mathrm{IV})$ in $\mathrm{TiO}_{2}\left(\mathrm{Ti} 2 \mathrm{p}_{3 / 2}=458.5 \mathrm{eV}\right)$ [47]. This can be attributed to the specific charging of the incorporated $\mathrm{TiO}_{2}$ into the polymer matrix coupled with the low signal intensity. The derived Ti-content from these is 0.2 at $\%$ (where the theoretical value is 0.7 at $\%$ ). Similar to the previous results (Figure 2), the XPS spectrum of $\mathrm{Ag}-\mathrm{TiO}_{2} / \mathrm{PDMS}-g r$-PNIPAAm (1.2 wt $\%$ INI; 5 M NIPAAm) still does not contain any peaks related to surface nitrogen; however, the element could be detected during EDX measurements in this case, as well (Figure 4). According to the recorded SEM images (Figure 4), the incorporated photocatalyst nanoparticles also enhance the surfaces with considerable surface roughness, which affected the surface wetting properties, as is detailed in the following section.

The detailed results of the XPS and EDX elemental analyses are shown in Table 2 and 3.

\subsection{Thermoresponsive and composition-dependent wetting properties}

As it is already well known, the PNIPAAm owes its thermoresponsive wetting characteristics to its LCST 


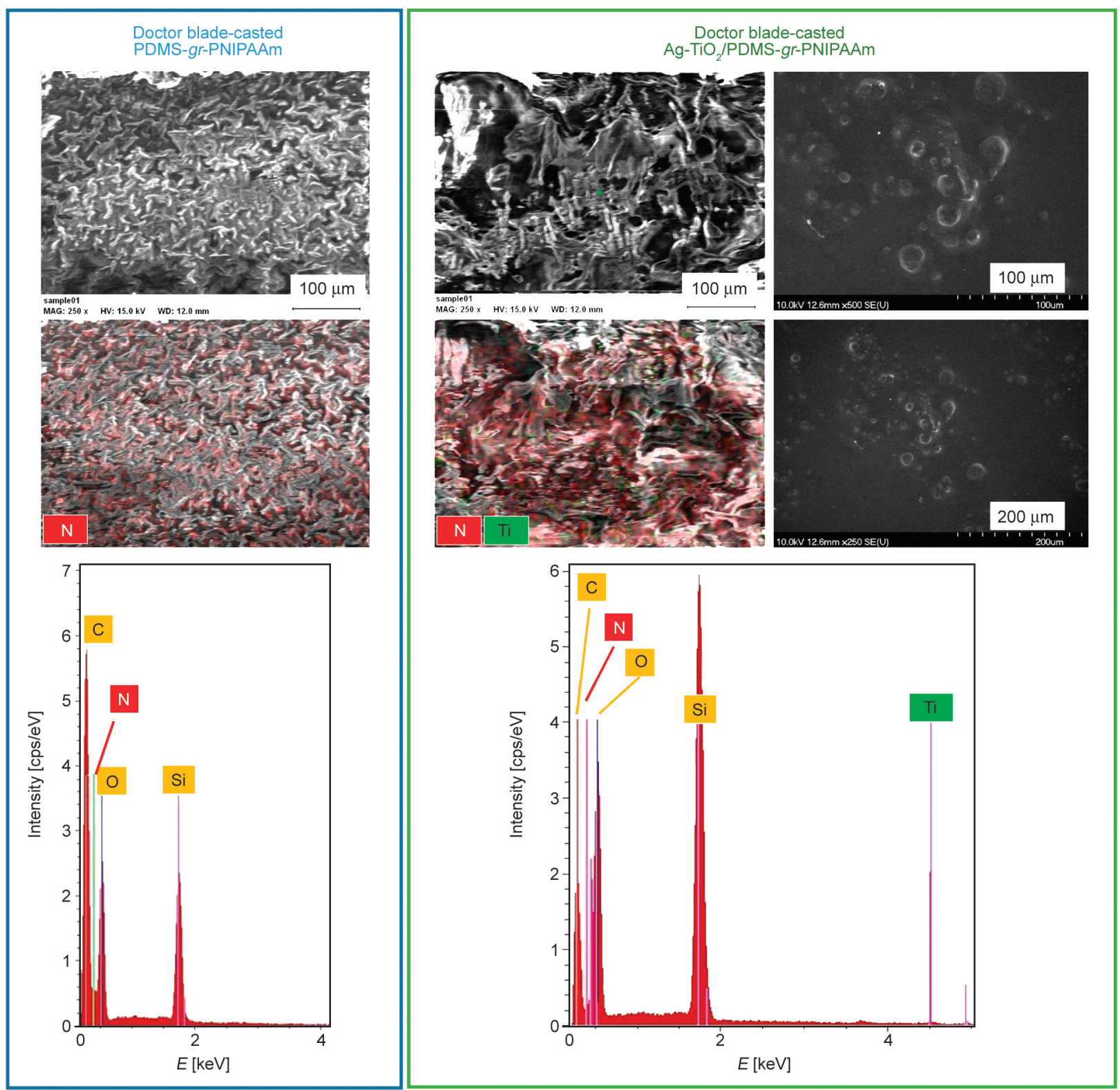

Figure 4. EDX-spectra and SEM-images of PDMS- $g r$-PNIPAAm and Ag-TiO $2 / P D M S-g r$-PNIPAAm surfaces $(1.2 \mathrm{wt} \%$ INI; 5 M NIPAAm) with the distribution of nitrogen and titanium.

Table 3. Elemental composition of different PDMS-based doctor blade-casted layers ( $1.2 \mathrm{wt} \%$ INI; 5 M NIPAAm) based on EDX spectral data.

\begin{tabular}{|l|c|c|c|c|}
\hline \multirow{3}{*}{ Element } & \multicolumn{4}{|c|}{$\begin{array}{c}\text { Elemental composition } \\
\text { [at\%] }\end{array}$} \\
\cline { 2 - 5 } & PDMS-co-INI & Ag-TiO $_{2}$ /PDMS-co-INI & PDMS-gr-PNIPAAm & Ag-TiO $_{2}$ /PDMS-gr-PNIPAAm \\
\hline Silicon & 7.9 & 13.8 & 6.5 & 9.3 \\
\hline Oxygen & 85.8 & 60.3 & 44.8 & 72.2 \\
\hline Carbon & 6.3 & 25.7 & 31.2 & 6.3 \\
\hline Nitrogen & - & - & 17.5 & 12.0 \\
\hline Titanium & - & 0.2 & - & 0.2 \\
\hline
\end{tabular}

at $\sim 32^{\circ} \mathrm{C}$, above which entropy-controlled precipitation occurs. In the case of our PDMS- $g r$-PNIPAAm (4.3 $\mathrm{wt} \%$ INI) films, the heat effect of the desolvation of surface PNIPAAm-chains can be measured by DSC in the case of samples, prepared to apply higher monomer concentrations ( $>2.5$ M NIPAAm) during grafting: Figure $5 \mathrm{a}$ indicates, that the measured LCST on the PNIPAAm-grafted polymer surfaces is somewhat higher (endothermic peak at $\sim 34^{\circ} \mathrm{C}$ ) than in the case of the two-component PNIPAAm-water 

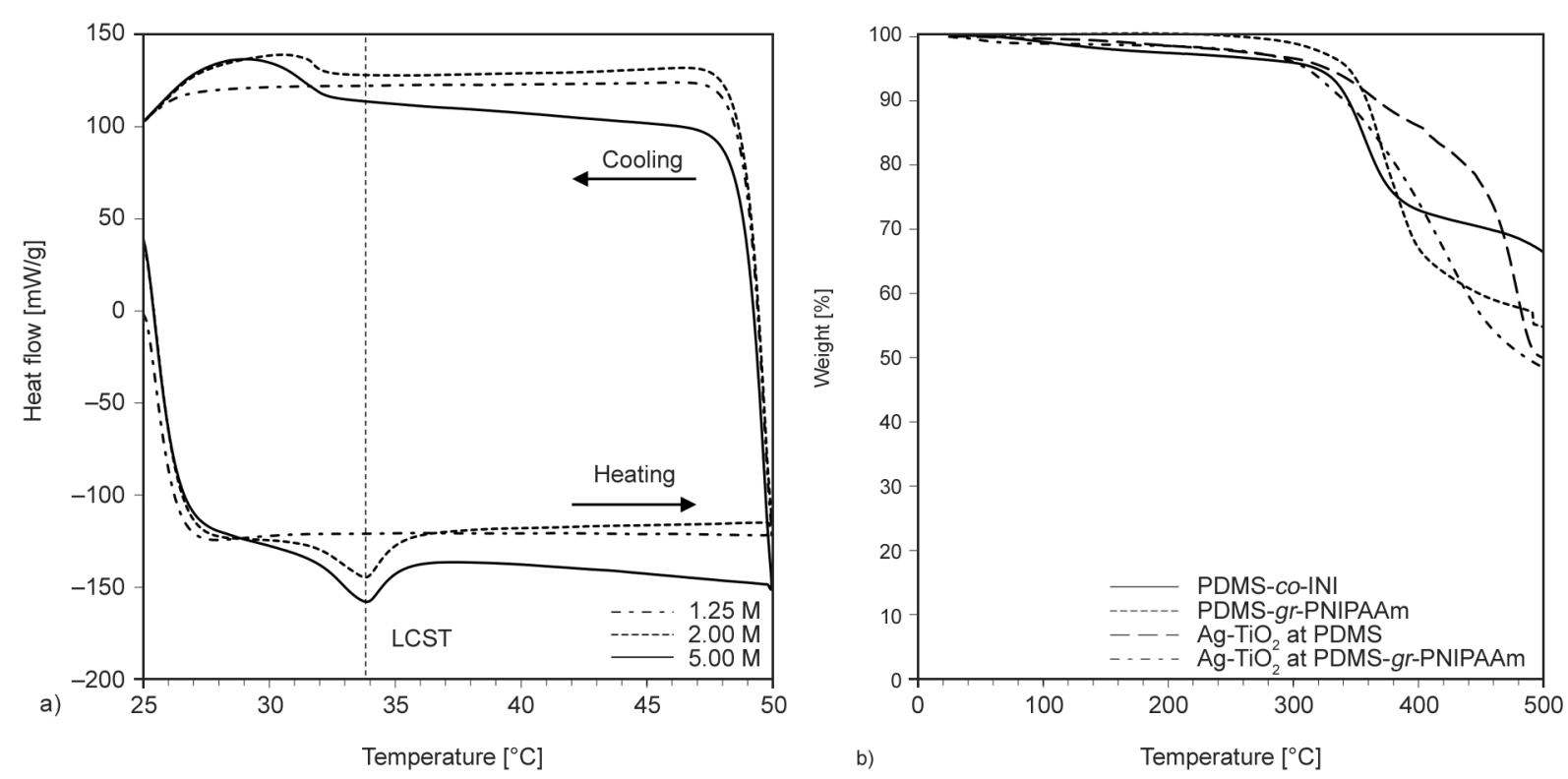

Figure 5. a) DSC curves of PDMS- $g r$-PNIPAAm (4.3 wt $\%$ INI; $1.25,2.00$ and 5 M NIPAAm) films and b) TG curves of PDMS-co-INI, PDMS-gr-PNIPAAm (4.3 wt $\%$ INI; 5 M NIPAAm) and their composites containing $15 \mathrm{wt} \% \mathrm{Ag}^{-\mathrm{TiO}_{2}}$.

systems $\left(\sim 32^{\circ} \mathrm{C}\right)$ [48], which can be attributed to the applied relatively high $\left(2{ }^{\circ} \mathrm{C} / \mathrm{min}\right)$ heating- and cooling speed during the DSC measurements. However, it is noteworthy that the temperatures of the peak maxima of the heating and cooling (exothermic peak of dissolution at $29-30^{\circ}$ ) processes give the expected average of $\sim 32^{\circ}$. The heat effect of the dissolution could only be detected when samples with higher $(>2.5 \mathrm{M})$ monomer concentrations were examined. Moreover, the prepared surfaces showed excellent thermal stability up to more than $300^{\circ} \mathrm{C}$ in an air atmosphere ( $T G$-curves of Figure $5 \mathrm{~b}$ ), which indicates their applicability in broad temperature ranges.

After proving the presence of PNIPAAm chains on the PDMS surfaces by means of DSC and the other analytical methods mentioned in Section 3.1. the PNIPAAm-influenced wetting properties were studied in detail.

To quantify the thermally induced changes in wetting characteristics, c.a. measurements were conducted on the PNIPAAm-grafted surfaces at 25, 40, and in some cases at 50 and $60^{\circ} \mathrm{C}$, applying the sessile drop technique. According to our observations at room temperature, the water droplets on the PNIPAAm-containing surfaces initially possess c.a.s similar to the ones characteristic to the pure, smooth PDMS surfaces $\left(\sim 105^{\circ}\right)$, but they gradually decrease over time until reaching a minimum quasi-equilibrium value, after approximately $1 \mathrm{~min}$. As Figure 6 shows, this contact-angle decline is dependent on the grafting monomer concentration, as higher NIPAAm concentrations lead to longer PNIPAAm-chains and, therefore, increased adhesion and wettability towards the sessile water droplets (up to $31.9^{\circ}$ c.a. difference between the $1 \mathrm{~min}$ wettabilities at 25). The time-dependency of c.a.s and non-immediate spreading of the droplets could be explained by the gradual solvation of surface-bonded PNIPAAm chains, which is attributed to the solvent-induced reorientation [49]: in a non-wetted state, the hydrophobic backbone of the polymer is oriented towards the air, while the aqueous medium interacts with the hydrophilic amide groups, causing the observed hydrophobic-tohydrophilic transitions over time. At $40^{\circ} \mathrm{C}$ this c.a. decrease is less significant $\left(4.6^{\circ}\right)$ as the temperature is above the LCST and the solvation of PNIPAAm does not occur (Figure 6).

Another c.a.-influencing factor is the rate of droplet evaporation: Figure 6 also shows that above $40^{\circ} \mathrm{C}$, the increased evaporation rate results in more decreased c.a.-values after 1 min time intervals.

Figure 6 also evidences the expected thermoresponsive wetting characteristics of the PDMS-grPNIPAAm surfaces: the equilibrium c.a.-values are higher above the LCST, which means a more hydrophobic character as the surface-bounded PNIPAAm chains and the water become immiscible with each other (c.a.s ranged from 50.72 to $108.73^{\circ}$ ).

In the case of $\mathrm{Ag}-\mathrm{TiO}_{2} / \mathrm{PDMS}-\mathrm{g} r$-PNIPAAm films, the same wetting tendencies can be observed (Figure 6); however, the c.a.-values of the spraycoated layers in general, cover a broader range (even 


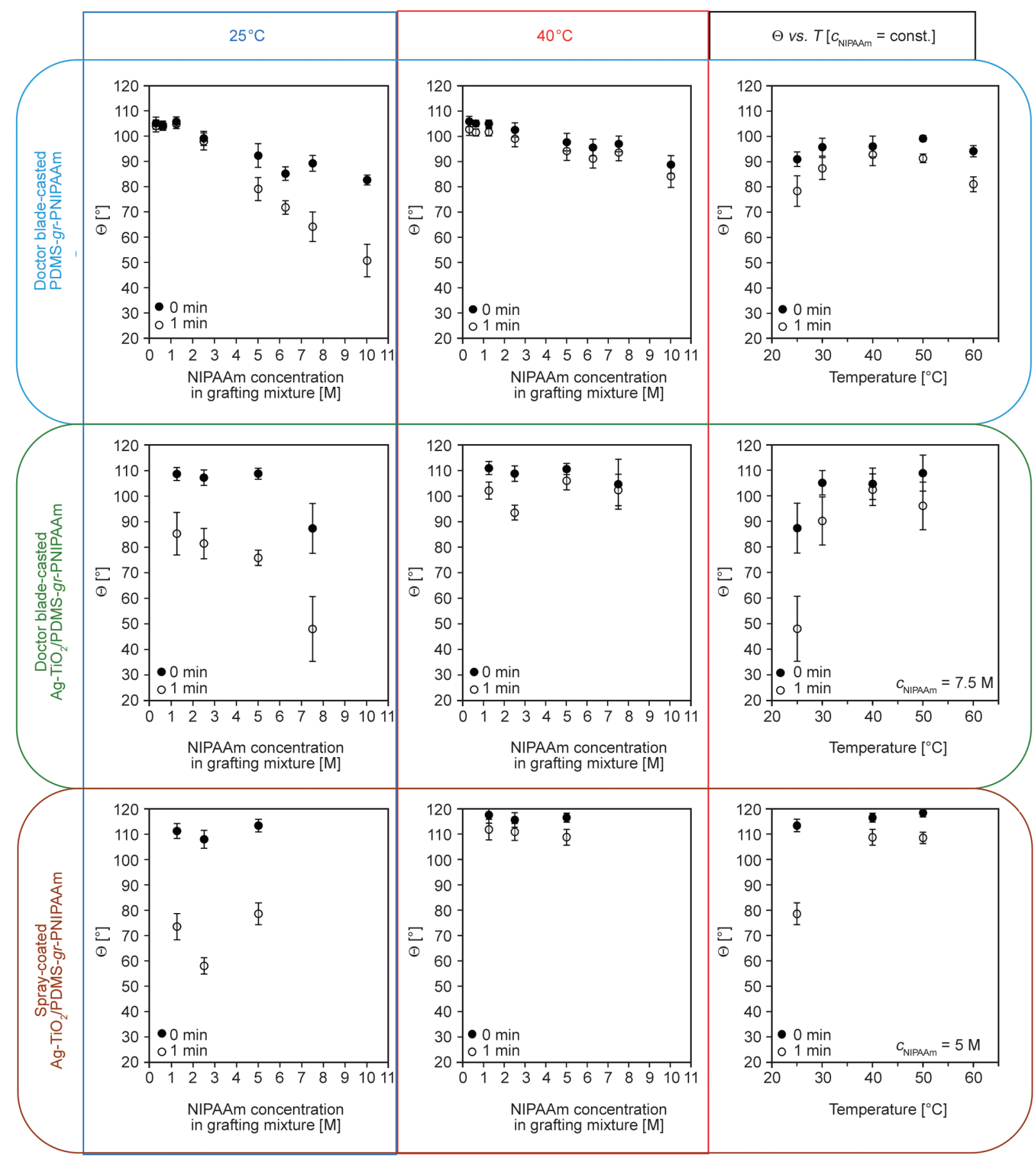

Figure 6. c.a. values $(\Theta)$ of doctor blade-casted and spray-coated PDMS-gr-PNIPAAm layers and c.a.s of spray-coated Ag$\mathrm{TiO}_{2} /$ PDMS-gr-PNIPAAm layers $(4.3 \mathrm{wt} \% \mathrm{INI})$ as a function of NIPAAm concentration in the grafting mixture, both at 25 and $40^{\circ} \mathrm{C}$ with example $\Theta v s . T$ diagraphs at constant monomer concentration (right column).

at lower PNIPAAm monomer concentrations) with the changing temperature: this can be explained by the increased surface roughness due to the addition of the photocatalyst nanoparticles [50]. This microand nanoscale roughness of a surface can generally emphasize the initially hydrophobic or hydrophilic nature [51]. As the addition of $\mathrm{Ag}-\mathrm{TiO}_{2}$ particles decreased the adhesion between the PDMS- films and the glass substrates, the maximum applicable
NIPAAm monomer concentration was proven to be 7.5 $\mathrm{M}$ in the grafting mixtures: above this concentration, the polymer films detached from the substrates. This detachment can be attributed to the increase in surface waviness during grafting (it can be observed in Figure 4), and the resulting decrease in the contact area between the films and the substrates. This maximum acceptable concentration of NIPAAm was proven to be even lower $(5 \mathrm{M})$ in the case of 
spray-coated $\mathrm{Ag}-\mathrm{TiO}_{2} / \mathrm{PDMS}$ - $g r$-PNIPAAm layers (Figure 6) as the photocatalyst particles are more homogenously dispersed in these systems, which can result in a more significant decrease of film-substrate contact area and adhesion, which can lead to the detachment of the layers. This more homogenous distribution of the photocatalyst particles is reflected in the results of c.a. measurements: as it can be seen in Figure 6, the c.a. standard deviations (represented by the error bars) are smaller than in the case of doctor blade-casted films (Figure 6). Moreover, the spraycoated films have higher achievable c.a. values (even $117.5^{\circ}$ at $0 \mathrm{~min}$ ) over the LCST (Figure 6), which also proves the roughness-enhanced hydrophobic character.

Besides the presented c.a. values of different Ag$\mathrm{TiO}_{2} /$ PDMS- $g r$-PNIPAAm (1.2 wt $\%$ INI) layers, the c.a. values of $4.3 \mathrm{wt} \%$ INI-containing films were also measured and in their case the similar trends were observed. As the overall stability of the $1.2 \mathrm{wt} \% \mathrm{INI}$ layers was proven to be better than their $4.3 \mathrm{wt} \% \mathrm{INI}$ counterparts', we decided to utilize these compositions in the following MB photodegradation tests; therefore the wetting properties of $4.3 \mathrm{wt} \%$ INI-containing systems are not discussed in detail.

\subsection{Thermoresponsive photocatalytic performance}

As the rate of heterogeneous photocatalytic reactions at the $\mathrm{S} / \mathrm{L}$-interface could be dependent on many factors, including the wettability of the solid surface by the liquid medium [46], the above-presented thermoresponsive wetting characteristics could - nonsurprisingly - influence the photocatalytic performance of spray-coated $\mathrm{Ag}-\mathrm{TiO}_{2} / \mathrm{PDMS}-\mathrm{g} r$-PNIPAAm films, as well, which was proved by MB-photodegradation tests below $\left(25^{\circ} \mathrm{C}\right)$ and above $\left(50^{\circ} \mathrm{C}\right)$ the LCST of surface PNIPAAm.

The upper limit of the photocatalyst-content of the examined composite layers $\left(d=19 \mathrm{mg} / \mathrm{cm}^{2}\right)$ was set to $15 \mathrm{wt} \%$ due to the extreme decline in mechanical durability and adhesive properties we experienced in the case of films with higher $\mathrm{Ag}-\mathrm{TiO}_{2-}$ amounts. The PDMS:INI -ratio was also proven to be critical when it comes to durability: as the incorporated nanoparticles and their aggregates also lower the cross-linking density, compositions with higher PDMS: INI-ratios are preferred in order to provide adequate mechanical integrity and adhesion to the supporting glass surface. Therefore, only spray-coated Ag-TiO $2 /$ PDMS-gr-PNIPAAm (1.2 wt $\%$ INI; 5 M NIPAAm) layers were prepared for MBphotodegradation tests to avoid as much damage as possible during the experiments.

MB is a popular model pollutant in photodegradation scenarios, as it is not only an industrially relevant wastewater component [52], but it has several other advantages in simple laboratory experiments. Its concentration can easily be followed by UV-VIS spectrophotometry [53] and if the $\mathrm{pH}$ is neutral and the solution contains enough oxygen, the decolorization of MB can only be attributed to the mineralization. This allows a relatively exact determination of photocatalytic efficiency [53]. The emission intensity of the exciting light source should be low in the $\lambda=350$ $480 \mathrm{~nm}$ range to hinder direct MB photolysis [53]: the applied LED light source fulfilled this requirement with an emission maximum at $\lambda=405 \mathrm{~nm}$. As $\mathrm{TiO}_{2}$ has the point of zero charge $(\mathrm{PZC})$ at $\mathrm{pH} \approx 6$, the adsorption of the positively charged MB molecules to the negatively charged catalyst surface at $\mathrm{pH} \approx 7$ is preferred [54].

In our previous publications, we discussed that the applied photocatalyst nanoparticles possess visible light-absorbing capabilities $\left(E_{\mathrm{g}}=3.08 \mathrm{eV}\right)$ due to the $0.5 \mathrm{wt} \%$ plasmonic AgNP-content [35]. As their composite surfaces were proven to be effective in several MB-photodegradation scenarios, when blue LED lamps $\left(\lambda_{\max }=405 \mathrm{~nm}\right)$ were applied as light sources $[11,44,45]$, we conducted this study under similar conditions.

The recorded relative concentration vs. illumination time curves can be seen on Figure 7. As Figure 7a shows, the photolysis of MB unsurprisingly has a higher reaction rate at 50 than at $25^{\circ} \mathrm{C}$. The thermoresponsive photocatalytic behaviour of $\mathrm{Ag}-\mathrm{TiO}_{2} / \mathrm{PDMS}-$ $g r$-PNIPAAm films is indicated by the differences between the MB-photodegradation efficiencies of the illuminated films and the photolysis (the direct photodegradation of MB) at different temperatures. Figure 7b) shows that the photodegradation efficiency of the layers is the same as the efficiency of the photolysis at $50{ }^{\circ} \mathrm{C}$, while there is a $15.5 \%$ difference between the efficiency of $\mathrm{Ag}$ - $\mathrm{TiO}_{2}$-assisted photocatalytic degradation and the photolysis at $25^{\circ} \mathrm{C}$ (Figure 7c). This practically means the nullification of the photocatalytic effect of $\mathrm{Ag}-\mathrm{TiO}_{2}$ nanoparticles. As it can be seen in Figure 7a, the determined 15.5\% difference in photodegradation efficiency can be considered as significant as the standard deviations of 

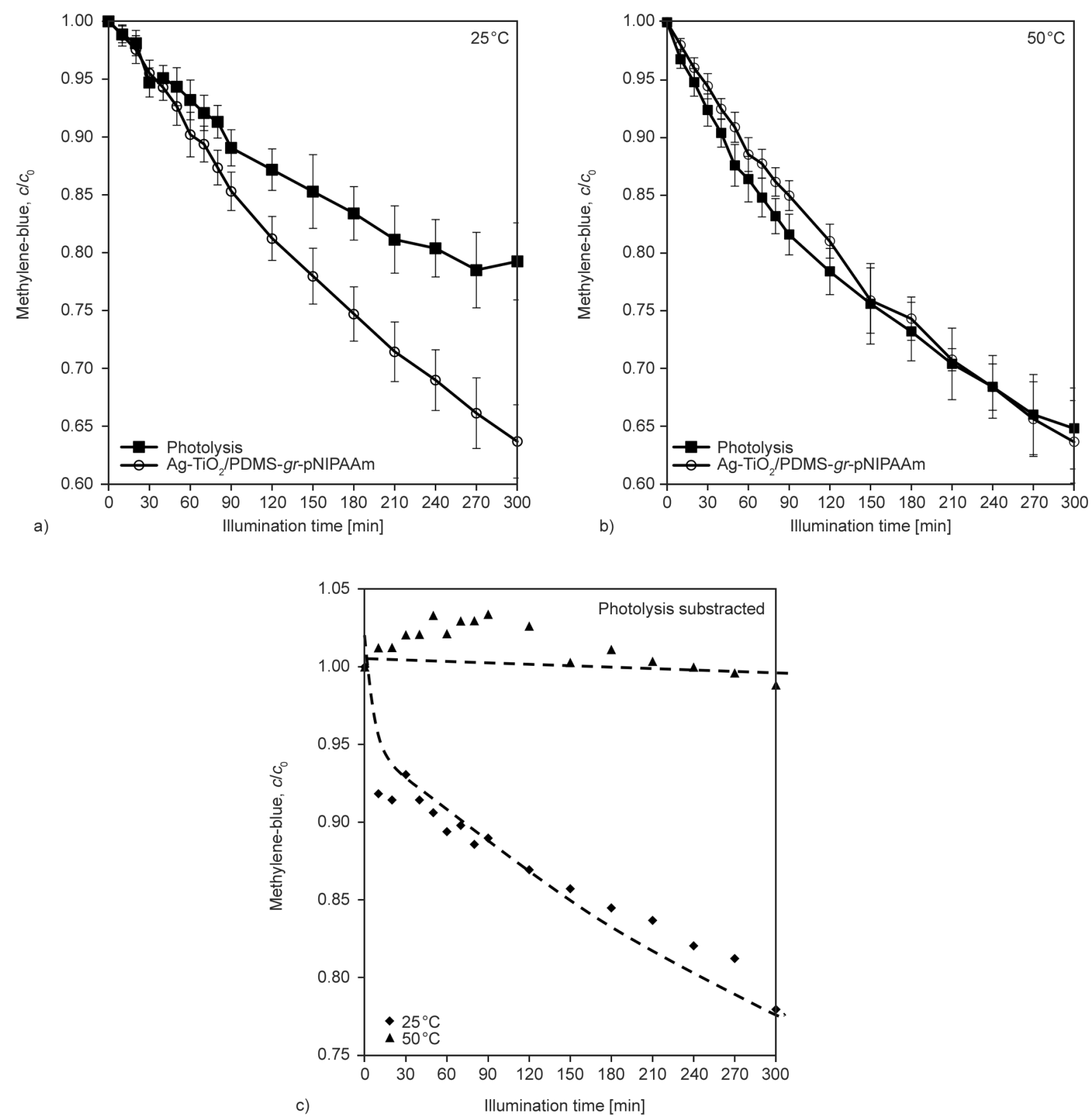

Figure 7. Characteristic photodegradation curves of $\mathrm{MB}$ at the $\mathrm{S} / \mathrm{L}$-interface upon blue LED-light $\left(\lambda_{\max }=405 \mathrm{~nm}\right)$ illumination at a) 25 , b) $50{ }^{\circ} \mathrm{C}$ and c) at both temperatures after the subtraction of photolyzed concentration; relative MBconcentration $\left(c_{0}=2 \mathrm{mg} / \mathrm{l}=6.25 \mathrm{mM}\right) v s$. illumination time. The corresponding curves for MB photolysis and photodegradation by the help of Ag-TiO 2 /PDMS-gr-PNIPAAm (1.2 wt $\%$ INI; 5 M NIPAAm) are both displayed.

the relative concentrations (represented by the error bars), determined during 3 parallel measurements for each sample and temperature do not overlap.

According to an example for thermoresponsive photocatalytic particles from the literature, the nullification of photoreactivity can be explained by the hindered diffusion of the water-soluble dye molecules to the photocatalyst surface as the covering PNIPAAmchains collapse and block the surface at temperatures over the LCST [18]. This proposed mechanism is depicted in Figure 8. However, it is also important to note that in similar photoreactive coatings, the surface of photocatalyst particles is mostly covered in the matrix material [46] (also depicted in Figure 8), which may photodegrade over time, resulting in a gradually increasing photodegradation efficiency towards the model pollutants as the photocatalyst particles become more exposed to incident light.

To support the obtained contact angle and photodegradation efficiency data, the surface free energy values $\left(\gamma_{\text {tot }}\right)$ of the examined photoreactive composites were also determined. As Figure 9a shows, the 


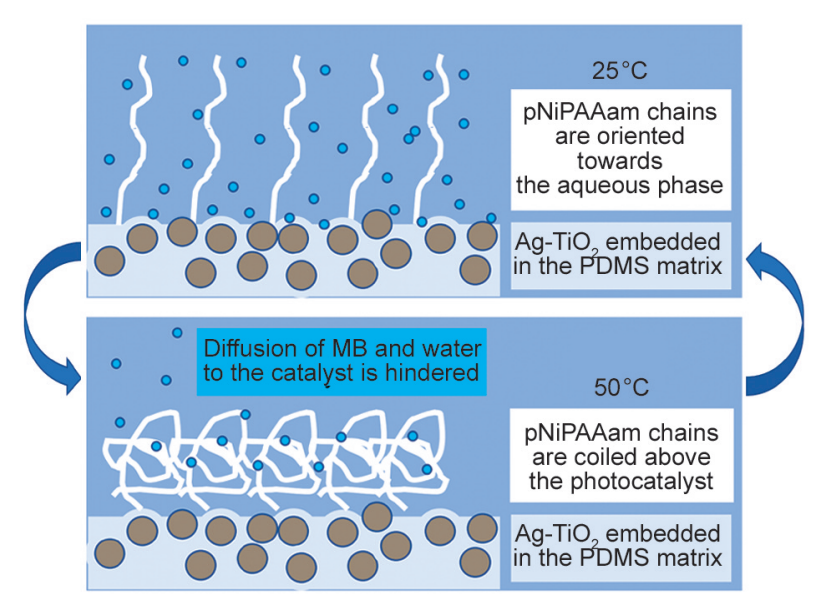

Figure 8. Proposed behavior of the $\mathrm{AgTiO}_{2} / \mathrm{PDMS}-g r$ PNIPAAm composite surfaces in aqueous MB-solutions. The figure also represents the partial coverage of photocatalyst particle surfaces by the matrix material.

advancing $\left(\Theta_{\text {adv }}\right)$ and receding $\left(\Theta_{\text {rec }}\right)$ c.a.s at different temperatures do not differ significantly in the case of Ag-TiO $2 / \mathrm{PDMS}$-co-INI (Figure 9a); however, the dynamic c.a.s on $\mathrm{Ag}-\mathrm{TiO}_{2} / \mathrm{PDMS}-g r$-PNIPAAm
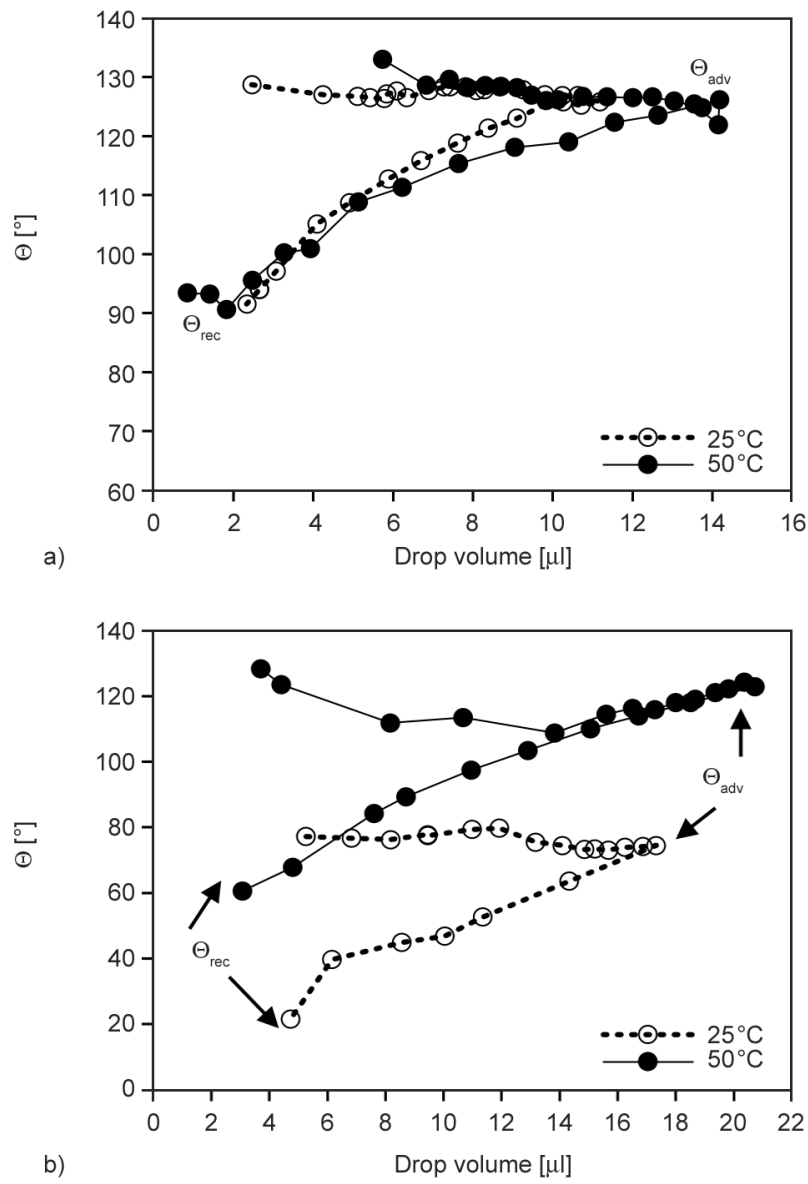

(Figure 9b) increase as the temperature is elevated from 25 to $50^{\circ} \mathrm{C}$. The calculated $\left(\gamma_{\mathrm{s}}^{\text {tot }}\right)$ values are in good accordance with the wetting and photocatalytic experiments: while the $\gamma_{\mathrm{s}}^{\text {tot }}$ of $\mathrm{Ag}-\mathrm{TiO}_{2} / \mathrm{PDMS}-$ coINI shows a slight decrease upon temperature-increase (from $7.54 \pm 0.42$ to $4.71 \pm 0.47 \mathrm{~mJ} / \mathrm{m}^{2}$ ), this decrease is more emphasized in the case of Ag$\mathrm{TiO}_{2} /$ PDMS- $g r$-PNIPAAm (from $42.12 \pm 5.75$ to $8.22 \pm 1.25 \mathrm{~mJ} / \mathrm{m}^{2}$ ) (Figure 9c). This surface-free energy difference can also be the reason behind the different photodegradation efficiencies, as higher energy surfaces promote wetting and the adsorption of photocatalytic substrates, in general.

On the other hand, the observed photodegradation efficiencies may also be influenced by the temperature-dependent UV-VIS absorbance and thermal degradation of the MB solutions $[55,56]$. To examine this possibility, the UV-VIS spectra of the dye solutions were measured at both 25 and $50{ }^{\circ} \mathrm{C}$ and after 5 hours of $50^{\circ} \mathrm{C}$ heat treatment. As Figure 10a shows, the relative intensities of absorption peaks are barely influenced by the temperature in the $25-50^{\circ} \mathrm{C}$-range;

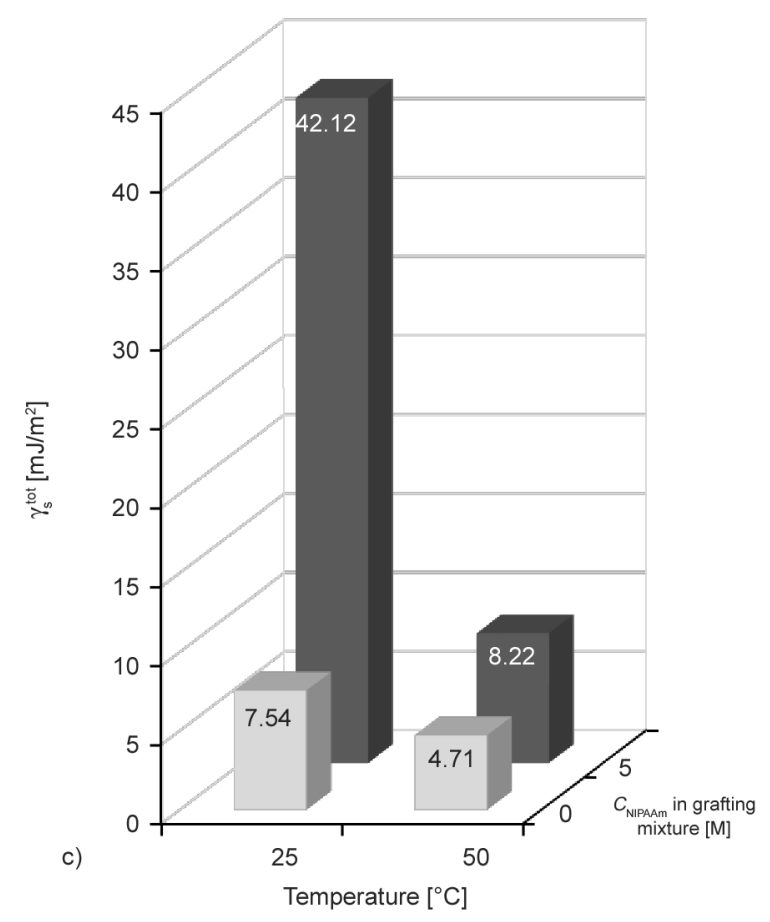

Figure 9. Water contact angles as a function of drop volume on a) $\mathrm{Ag}-\mathrm{TiO}_{2} / \mathrm{PDMS}-\mathrm{co}-\mathrm{INI}$ and b) on $\mathrm{Ag}-\mathrm{TiO}_{2} / \mathrm{PDMS}-\mathrm{gr}$ PNIPAAm (5 M NIPAAm) layers at 25 and $50^{\circ} \mathrm{C}$ and c) the calculated surface free energy $\left(\gamma_{\mathrm{s}}^{\text {tot }}\right)$ values as a function of temperature and the grafting NIPAAm concentrations. ( $0 \mathrm{M}$ for $\left.\mathrm{Ag}-\mathrm{TiO}_{2} / \mathrm{PDMS}-\mathrm{co}-\mathrm{INI}\right)$. 

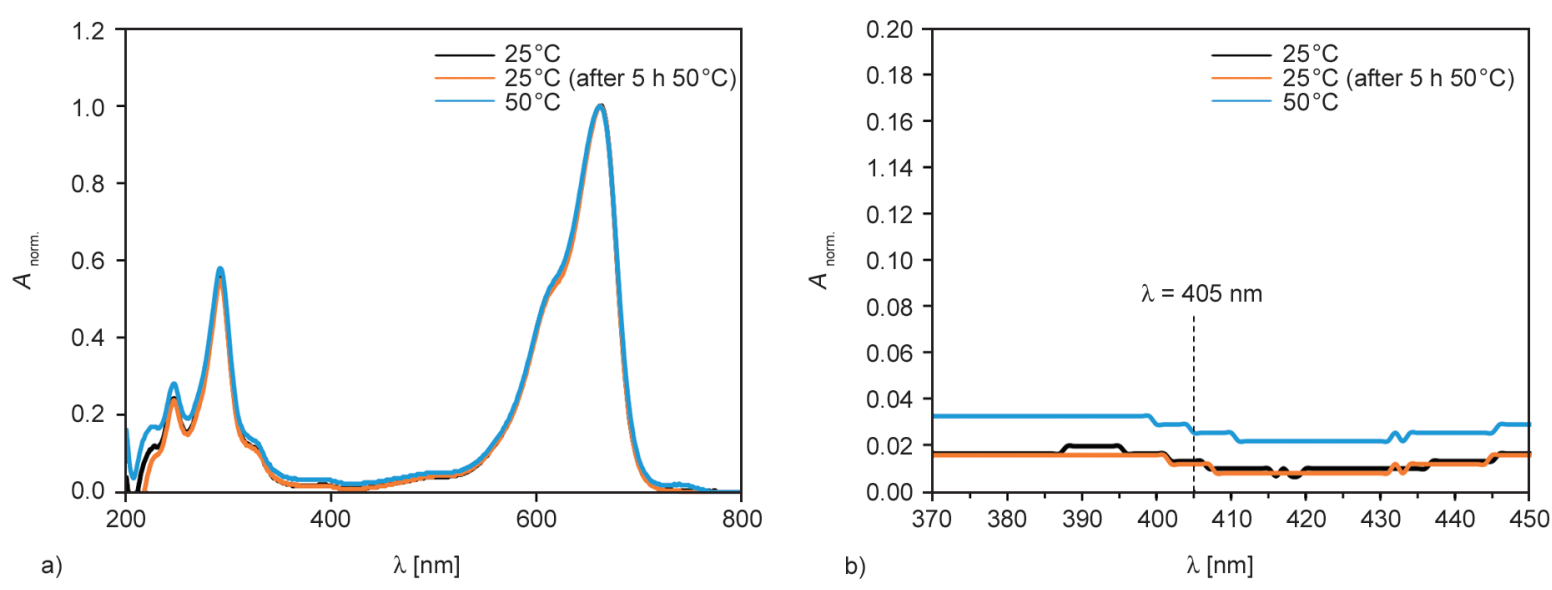

Figure 10. a) Normalized UV-VIS spectra of $c_{0}=2 \mathrm{mg} / \mathrm{dm}^{3}$ or $6.25 \mu \mathrm{M} \mathrm{MB}$ solution at $25,50^{\circ} \mathrm{C}$ and at $25^{\circ} \mathrm{C}$ after 5 hours of storage at $50^{\circ} \mathrm{C}$ and $\left.\mathrm{b}\right)$ the absorptions at wavelengths near the emission wavelength $(\lambda=405 \mathrm{~nm})$ of the applied LED light source.

however, a minor increase in the absorption around $\lambda=405 \mathrm{~nm}$ was observed Figure 10b, which may contribute to the higher rate of direct MB-photolysis at $50^{\circ} \mathrm{C}$ (Figure 7). As the spectrum of the MB solution did not show changes either after the $5 \mathrm{~h} 50^{\circ} \mathrm{C}$ treatment (Figure 10), the thermal degradation during the photocatalytic experiments can be considered negligible.

\section{Conclusions}

In this study, we prepared multifunctional thermoresponsive $\left(25-50^{\circ} \mathrm{C}\right.$ range) composite coatings with real-time tunable wetting properties (achieved c.a.s ranged from 50.7 to $108.9^{\circ}$ ) and visible light-photoreactivity (blue LED-light, $\lambda=405 \mathrm{~nm}$ ) at the $\mathrm{S} / \mathrm{L}$ interface during methylene-blue (MB) degradation tests. The wettability of the surfaces also turned out to be dependent on the concentration of the grafting NIPAAm-monomer. Besides the contact angle measurements and the photodegradation tests, the samples were characterized by applying SEM, XPS, EDX, Raman-spectroscopy, DSC, and oscillatory rheology measurement techniques.

Our work is the first example of PNIPAAm-decorated macroscopic surfaces with both features in the literature. Therefore, these materials should be further examined before broader-scale application, which implies possible future liquid manipulation studies, such as selective photodegradation of certain chemical species in oil-water systems, where the wettability of the surface towards the different phases is regulated by temperature.

The preparation process of these composites consists of two simple steps: variable spray-coating/film casting and immersion into the grafting solution (the high-temperature curing can be omitted by the right choice of PDMS prepolymers), which may offer high versatility upon the upscaling of the process. As PDMS is also a common and easy-to-process base material of microfluidic tubings and channels [57] and PNIPAAm was also applied in such scenarios [58], these composites may seek future at this field as elements of sophisticated microchannel-systems or reactors, as well.

\section{Acknowledgements}

This work was supported by the National Research, Development and Innovation Office; under Grant number GINOP2.3.2-15-2016-00013 and number GINOP-2.1.7-15-201601987; New National Excellence Program of the Ministry for Innovation and Technology through the National Research, Development and Innovation Fund; under Grant number UNKP-20-5, number UNKP-20-4 and number UNKP20-3; Hungarian Academy of Sciences; under the János Bolyai Research Scholarship of the; Ministry of Human Capacities, Hungary; under Grant number 20391-3/2018/ FEKUSTRAT (G. Katona).

Prepared with the professional support of the Doctoral Student Scholarship Program of the Co-operative Doctoral Program of the Ministry of Innovation and Technology financed from the National Research, Development and Innovation Fund.

\section{References}

[1] Yu H., Feng Y., Chen C., Zhang Z., Cai Y., Qin M., Feng W.: Thermally conductive, self-healing, and elastic polyimide@vertically aligned carbon nanotubes composite as smart thermal interface material. Carbon, 179, 348-357 (2021).

https://doi.org/10.1016/j.carbon.2021.04.055 
[2] Zhang F., Feng Y., Feng W.: Three-dimensional interconnected networks for thermally conductive polymer composites: Design, preparation, properties, and mechanisms. Materials Science and Engineering R: Reports, 142, 100580 (2020). https://doi.org/10.1016/j.mser.2020.100580

[3] Janovák L., Tallósy S. P., Sztakó M., Deák A., Bitó T., Buzás N., Bártfai G., Dékány I.: Synthesis of pH-sensitive copolymer thin solid films embedded with silver nanoparticles for controlled release and their fungicide properties. Journal of Drug Delivery Science and Technology, 24, 628-636 (2014). https://doi.org/10.1016/S1773-2247(14)50129-3

[4] Yu W., Lou L-L., Li S., Ma T., Ouyang L., Feng L., Liu S.: Highly efficient and durable platinum nanocatalysts stabilized by thiol-terminated poly( $N$-isopropyl acrylomide) for selective hydrogenation of halonitrobenzene to haloaniline. RSC Advances, 7, 751-757 (2017). https://doi.org/10.1039/C6RA24773C

[5] Sénéchal V., Saadaoui H., Rodriguez-Hernandez J., Drummond C.: Electrowetting of weak polyelectrolytecoated surfaces. Langmuir, 33, 4996-5005 (2017). https://doi.org/10.1021/acs.langmuir.7b00473

[6] Zhou Y., Zheng Y., Wei T., Qu Y., Wang Y., Zhan W., Zhang Y., Pan G., Li D., Yu Q., Chen H.: Multistimulus responsive biointerfaces with switchable bioadhesion and surface functions. ACS Applied Materials and Interfaces, 12, 5447-5455 (2020). https://doi.org/10.1021/acsami.9b18505

[7] Wang Y., Song C., Yu X., Liu L., Han Y., Chen J., Fu J.: Thermo-responsive hydrogels with tunable transition temperature crosslinked by multifunctional graphene oxide nanosheets. Composites Science and Technology, 151, 139-146 (2017). https://doi.org/10.1016/j.compscitech.2017.08.016

[8] Fu Q., Rama Rao G. V., Basame S. B., Keller D. J., Artyushkova K., Fulghum J. E., López G. P.: Reversible control of free energy and topography of nanostructured surfaces. Journal of the American Chemical Society, 126, 8904-8905 (2004). https://doi.org/10.1021/ja047895q

[9] Zhang D., Cheng Z., Kang H., Yu J., Liu Y., Jiang L.: A smart superwetting surface with responsivity in both surface chemistry and microstructure. Angewandte Chemie International Edition, 57, 3701-3705 (2018). https://doi.org/10.1002/anie.201800416

[10] Sorokin V. V., Sokolov B. O., Stepanov G. V., Kramarenko E. Y.: Controllable hydrophobicity of magnetoactive elastomer coatings. Journal of Magnetism and Magnetic Materials, 459, 268-271 (2018). https://doi.org/10.1016/j.jmmm.2017.10.074

[11] Mérai L., Deák Á., Sebők D., Kukovecz Á., Dékány I., Janovák L.: A Stimulus-responsive polymer composite surface with magnetic field-governed wetting and photocatalytic properties. Polymers, 12, 1890 (2020). https://doi.org/10.3390/polym12091890
[12] Yang C., Wu L., Li G.: Magnetically responsive superhydrophobic surface: In situ reversible switching of water droplet wettability and adhesion for droplet manipulation. ACS Applied Materials and Interfaces, 10, 20150-20158 (2018).

https://doi.org/10.1021/acsami.8b04190

[13] Wan L., Meng X., Yang Y., Tian J., Xu Z.: Thermo-responsive stick-slip behavior of advancing water contact angle on the surfaces of poly( $N$-isopropylacrylamide)grafted polypropylene membranes. Science China Chemistry, 7, 183-189 (2010).

https://doi.org/10.1007/s11426-010-0004-4

[14] Andersson M., Hietala S., Tenhu H., Maunu S. L.: Polystyrene latex particles coated with crosslinked poly $(\mathrm{N}$ isopropylacrylamide). Colloid and Polymer Science, 284, 1255-1263 (2006).

https://doi.org/10.1007/s00396-006-1470-2

[15] Chen L., Liu M., Bai H., Chen P., Xia F., Han D., Jiang L.: Antiplatelet and thermally responsive poly $(N$-isopropylacrylamide) surface with nanoscale topography. Journal of the American Chemical Society, 131, 1046710472 (2009). https://doi.org/10.1021/ja9019935

[16] Cooperstein M. A., Canavan H. E.: Assessment of cytotoxicity of ( $\mathrm{N}$-isopropyl acrylamide) and poly $(\mathrm{N}$-isopropyl acrylamide)-coated surfaces. Biointerphases, 8 , 19 (2013). https://doi.org/10.1186/1559-4106-8-19

[17] Kurzhals S., Zirbs R., Reimhult E.: Synthesis and magneto-thermal actuation of iron oxide core-PNIPAM shell nanoparticles. ACS Applied Materials and Interfaces, 7, 19342-19352 (2015). https://doi.org/10.1021/acsami.5b05459

[18] Jia H., Roa R., Angioletti-Uberti S., Henzler K., Ott A., Lin X., Möser J., Kochovski Z., Schnegg A., Dzubiella J., Ballauff M., Lu Y.: Thermosensitive $\mathrm{Cu}_{2} \mathrm{O}$-PNIPAM core-shell nanoreactors with tunable photocatalytic activity. Journal of Materials Chemistry A, 4, 9677-9684 (2016).

https://doi.org/10.1039/C6TA03528K

[19] Lanzalaco S., Armelin E.: Poly( $N$-isopropylacrylamide) and copolymers: A review on recent progresses in biomedical applications. Gels, 3, 36 (2017).

https://doi.org/10.3390/gels3040036

[20] Huber R. O., Beebe J. M., Smith P. B., Howell B. A., Ahn D.: Facile synthesis of thermoresponsive poly (NIPAAm-g-PDMS) copolymers using room temperature alkylborane chemistry. Macromolecules, 51, 42594268 (2018).

https://doi.org/10.1021/acs.macromol.8b00252

[21] Lue S., Chen B-W., Shih C-M., Chou F-Y., Lai J-Y., Chiu W-Y.: Micron- and nano-sized poly( $N$-isopropylacrylamide-co-acrylic acid) latex syntheses and their applications for controlled drug release. Journal of Nanoscience and Nanotechnology, 13, 5305-5315 (2013). https://doi.org/10.1166/jnn.2013.7532 
[22] Kim Y. S., Kim M. A., Lee C-M.: Controlled drug release from PNIPAM-incorporated melanin nanovesicles by photo-stimulation. Materials Technology, 34, 639644 (2019).

https://doi.org/10.1080/10667857.2019.1611055

[23] Lee T. H., Jho J. Y.: Temperature-responsive actuators fabricated with PVA/PNIPAAm interpenetrating polymer network bilayers. Macromolecular Research, 26, 659-664 (2018).

https://doi.org/10.1007/s13233-018-6084-2

[24] Bakarich S. E., Gorkin R., in het Panhuis M., Spinks G. M.: 4D printing with mechanically robust, thermally actuating hydrogels. Macromolecular Rapid Communications, 36, 1211-1217 (2015). https://doi.org/10.1002/marc.201500079

[25] Shivapooja P., Ista L. K., Canavan H. E., Lopez G. P.: ARGET-ATRP synthesis and characterization of PNIPAAm brushes for quantitative cell detachment studies. Biointerphases, 7, 32 (2012). https://doi.org/10.1007/s13758-012-0032-Z

[26] Xiong X., Wu Z., Pan J., Xue L., Xu Y., Chen H.: A facile approach to modify poly(dimethylsiloxane) surfaces via visible light-induced grafting polymerization. Journal of Materials Chemistry B, 3, 629-634 (2015). https://doi.org/10.1039/C4TB01600A

[27] Xiao L., Isner A., Waldrop K., Saad A., Takigawa D., Bhattacharyya D.: Development of bench and full-scale temperature and $\mathrm{pH}$ responsive functionalized PVDF membranes with tunable properties. Journal of Membrane Science, 457, 39-49 (2014). https://doi.org/10.1016/j.memsci.2014.01.033

[28] Yu Q., Zhang Y., Chen H., Wu Z., Huang H., Cheng C.: Protein adsorption on poly( $N$-isopropylacrylamide)modified silicon surfaces: Effects of grafted layer thickness and protein size. Colloids and Surfaces B: Biointerfaces, 76, 468-474 (2010).

https://doi.org/10.1016/j.colsurfb.2009.12.006

[29] Sridhar S. P., Soman A. K., Sankaran T. S., Chandran S., Joseph B.: Temperature responsive poly $(N$-isopropylacrylamide-block-styrene) block copolymer coatings with tunable hydrophilicity. Surfaces and Interfaces, 21, 100800 (2020). https://doi.org/10.1016/j.surfin.2020.100800

[30] Kumar S., Dory Y. L., Lepage M., Zhao Y.: Surfacegrafted stimuli-responsive block copolymer brushes for the thermo-, photo- and $\mathrm{pH}$-sensitive release of dye molecules. Macromolecules, 44, 7385-7393 (2011). https://doi.org/10.1021/ma2010102

[31] Huo P., Li J., Ye Z., Wang H., Liu X., Li X., Yan Y.: Fabricated temperature sensitive photocatalyst of PNIPAM@ZnO/C for controllable photocatalytic activity. Chinese Chemical Letters, 28, 2259-2262 (2017). https://doi.org/10.1016/j.cclet.2017.09.067

[32] Liao W-P., Elliott I. G., Faller R., Kuhl T. L.: Normal and shear interactions between high grafting density polymer brushes grown by atom transfer radical polymerization. Soft Matter, 9, 5753-5761 (2013).

https://doi.org/10.1039/C3SM50261A
[33] Tallósy S. P., Janovák L., Nagy E., Deák Á., Juhász Á., Csapó E., Buzás N., Dékány I.: Adhesion and inactivation of gram-negative and gram-positive bacteria on photoreactive $\mathrm{TiO}_{2} /$ polymer and $\mathrm{Ag}-\mathrm{TiO}_{2} /$ polymer nanohybrid films. Applied Surface Science, 371, 139150 (2016).

https://doi.org/10.1016/j.apsusc.2016.02.202

[34] Tallósy S. P., Janovák L., Ménesi J., Nagy E., Juhász Á., Balázs L., Deme I., Buzás N., Dékány I.: Investigation of the antibacterial effects of silver-modified $\mathrm{TiO}_{2}$ and $\mathrm{ZnO}$ plasmonic photocatalysts embedded in polymer thin films. Environmental Science and Pollution Research, 21, 11155-11167 (2014).

https://doi.org/10.1007/s11356-014-2568-6

[35] Veres Á., Ménesi J., Juhász Á., Berkesi O., Ábrahám N., Bohus G., Oszkó A., Pótári G., Buzás N., Janovák L., Dékány I.: Photocatalytic performance of silvermodified $\mathrm{TiO}_{2}$ embedded in poly(ethyl-acrylate-comethyl metacrylate) matrix. Colloid and Polymer Science, 292, 207-217 (2014).

https://doi.org/10.1007/s00396-013-3063-1

[36] Drelich J.: Guidelines to measurements of reproducible contact angles using a sessile-drop technique. Surface Innovations, 1, 248-254 (2013).

https://doi.org/10.1680/si.13.00010

[37] Chibowski E.: Surface free energy of a solid from contact angle hysteresis. Advances in Colloid and Interface Science, 103, 149-172 (2003).

https://doi.org/10.1016/S0001-8686(02)00093-3

[38] Simonsen M. E., Sønderby C., Li Z., Søgaard E. G.: XPS and FT-IR investigation of silicate polymers. Journal of Materials Science, 44, 2079-2088 (2009).

https://doi.org/10.1007/s10853-009-3270-9

[39] Matyjaszewski K., Miller P. J., Shukla N., Immaraporn B., Gelman A., Luokala B. B., Siclovan T. M., Kickelbick G., Vallant T., Hoffmann H., Pakula T.: Polymers at interfaces: Using atom transfer radical polymerization in the controlled growth of homopolymers and block copolymers from silicon surfaces in the absence of untethered sacrificial initiator. Macromolecules, 32, 87168724 (1999).

https://doi.org/10.1021/ma991146p

[40] Beamson G., Briggs D.: High resolution XPS of organic polymers: The Scienta ESCA300 database. Wiley, New-York (1992).

[41] Wang L., Zhao X., Zhang Y., Zhang W., Ren T., Chen Z., Wang F., Yang H.: Fabrication of intelligent poly $(N$ isopropylacrylamide)/silver nanoparticle composite films with dynamic surface-enhanced Raman scattering effect. RSC Advances, 5, 40437-40443 (2015). https://doi.org/10.1039/C5RA04361A

[42] Wagner C. D.: Sensitivity of detection of the elements by photoelectron spectrometry. Analytical Chemistry, 44, 1050-1053 (1972).

https://doi.org/10.1021/ac60314a038 
[43] Paterson E., Swaffield R.: X-ray photoelectron spectroscopy. in 'Clay mineralogy: Spectroscopic and chemical determinative methods' (ed.: Wilson M. J.) Springer Netherlands, Dordrecht, 226-259 (1994).

https://doi.org/10.1007/978-94-011-0727-3 6

[44] Merai L., Deák A., Sebők D., Csapó E., Kolumbán T. S., Hopp B., Dékány, I., Janovák L.: Photoreactive composite coating with composition dependent wetting properties. Express Polymer Letters, 12, 1061-1071 (2018). https://doi.org/10.3144/expresspolymlett.2018.93

[45] Mérai L., Varga N., Deák Á., Sebők D., Szenti I., Kukovecz Á., Kónya Z., Dékány I., Janovák L.: Preparation of photocatalytic thin films with composition dependent wetting properties and self-healing ability. Catalysis Today, 328, 85-90 (2019). https://doi.org/10.1016/j.cattod.2018.10.015

[46] Lantos E., Mérai L., Deák Á., Gómez-Pérez J., Sebők D., Dékány I., Kónya Z., Janovák L.: Preparation of sulfur hydrophobized plasmonic photocatalyst towards durable superhydrophobic coating material. Journal of Materials Science and Technology, 41, 159-167 (2020). https://doi.org/10.1016/j.jmst.2019.04.046

[47] Biesinger M. C., Lau L. W. M., Gerson A. R., Smart R. S. C.: Resolving surface chemical states in XPS analysis of first row transition metals, oxides and hydroxides: Sc, Ti, V, Cu and Zn. Applied Surface Science, 257, $887-898$ (2010) https://doi.org/10.1016/j.apsusc.2010.07.086

[48] Zhang L., Zhang S., He B., Wu Z., Zhang Z.: TiO nanoparticles functionalized by a temperature-sensitive poly( $N$-isopropylacrylamide) (PNIPAM): Synthesis and characterization. Zeitschrift für Naturforschung B, 63, 973-976 (2008). https://doi.org/10.1515/znb-2008-0809

[49] Wang X., Chen Z., Shen Z.: Dynamic behavior of polymer surface and the time dependence of contact angle. Science in China Series B, 48, 553-559 (2005). https://doi.org/10.1360/042004-22

[50] Deák Á., Janovák L., Csapó E., Ungor D., Pálinkó I., Puskás S., Ördög T., Ricza T., Dékány I.: Layered double oxide (LDO) particle containing photoreactive hybrid layers with tunable superhydrophobic and photocatalytic properties. Applied Surface Science, 389, 294 302 (2016)

https://doi.org/10.1016/j.apsusc.2016.07.127
[51] Krumdieck S., Gorthy R., Gardecka A. J., Lee D., Miya S. S., Talwar S. D., Polson M. I. J., Bishop C.: Characterization of photocatalytic, wetting and optical properties of $\mathrm{TiO}_{2}$ thin films and demonstration of uniform coating on a $3-\mathrm{D}$ surface in the mass transport controlled regime. Surface and Coatings Technology, 326, 402-410 (2017).

https://doi.org/10.1016/j.surfcoat.2016.11.064

[52] Fito J., Abrham S., Angassa K.: Adsorption of methylene blue from textile industrial wastewater onto activated carbon of parthenium hysterophorus. International Journal of Environmental Research, 14, 501-511 (2020).

https://doi.org/10.1007/s41742-020-00273-2

[53] Tschirch J., Dillert R., Bahnemann D., Proft B., Biedermann A., Goer B.: Photodegradation of methylene blue in water, a standard method to determine the activity of photocatalytic coatings? Research on Chemical Intermediates, 34, 381-392 (2008).

https://doi.org/10.1163/156856708784040588

[54] Houas A., Lachheb H., Ksibi M., Elaloui E., Guillard C., Herrmann J-M.: Photocatalytic degradation pathway of methylene blue in water. Applied Catalysis B: Environmental, 31, 145-157 (2001).

https://doi.org/10.1016/S0926-3373(00)00276-9

[55] Fernández-Pérez A., Marbán G.: Visible light spectroscopic analysis of methylene blue in water; What comes after dimer? ACS Omega, 5, 29801-29815 (2020).

https://doi.org/10.1021/acsomega.0c03830

[56] Ahn C., Zeng X., Li L., Obendorf S. K.: Thermal degradation of natural dyes and their analysis using HPLCDAD-MS. Fashion and Textiles, 1, 22 (2014).

https://doi.org/10.1186/s40691-014-0022-5

[57] Hosokawa K., Sato K., Ichikawa N., Maeda M.: Powerfree poly(dimethylsiloxane) microfluidic devices for gold nanoparticle-based DNA analysis. Lab on a Chip, 4, 181-185 (2004). https://doi.org/10.1039/b403930k

[58] Koriyama T., Asoh T-A., Kikuchi A.: Preparation of a thermoresponsive polymer grafted polystyrene monolithic capillary for the separation of bioactive compounds. Colloids and Surfaces B: Biointerfaces, 147, 408-415 (2016).

https://doi.org/10.1016/j.colsurfb.2016.08.021 